\author{
SANDIA REPORT \\ SAND2010-2474 \\ Unlimited Release \\ Printed April 2010
}

\title{
Performance Characterization of a Hydrogen Catalytic Heater
}

Terry A. Johnson and Michael P. Kanouff

Prepared by

Sandia National Laboratories

Albuquerque, New Mexico 87185 and Livermore, California 94550

Sandia National Laboratories is a multi-program laboratory operated by Sandia Corporation, a wholly owned subsidiary of Lockheed Martin company, for the U.S.

Department of Energy's National Nuclear Security Administration under contract DE-AC04-94AL85000.

Approved for public release; further dissemination unlimited. 
Issued by Sandia National Laboratories, operated for the United States Department of Energy by Sandia Corporation.

NOTICE: This report was prepared as an account of work sponsored by an agency of the United States Government. Neither the United States Government, nor any agency thereof, nor any of their employees, nor any of their contractors, subcontractors, or their employees, make any warranty, express or implied, or assume any legal liability or responsibility for the accuracy, completeness, or usefulness of any information, apparatus, product, or process disclosed, or represent that its use would not infringe privately owned rights. Reference herein to any specific commercial product, process, or service by trade name, trademark, manufacturer, or otherwise, does not necessarily constitute or imply its endorsement, recommendation, or favoring by the United States Government, any agency thereof, or any of their contractors or subcontractors. The views and opinions expressed herein do not necessarily state or reflect those of the United States Government, any agency thereof, or any of their contractors.

Printed in the United States of America. This report has been reproduced directly from the best available copy.

Available to DOE and DOE contractors from

U.S. Department of Energy

Office of Scientific and Technical Information

P.O. Box 62

Oak Ridge, TN 37831

Telephone: $\quad$ (865) 576-8401

Facsimile: $\quad$ (865) 576-5728

E-Mail: $\quad$ reports@adonis.osti.gov

Online ordering: http://www.osti.gov/bridge

Available to the public from

U.S. Department of Commerce

National Technical Information Service

5285 Port Royal Rd.

Springfield, VA 22161

Telephone: (800) 553-6847

Facsimile: $\quad$ (703) 605-6900

E-Mail: $\quad$ orders@ntis.fedworld.gov

Online order: $\quad$ http://www.ntis.gov/help/ordermethods.asp?loc=7-4-0\#online

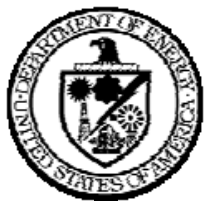


SAND2010-2474

Unlimited Release

Printed April 2010

\title{
Performance Characterization of a Hydrogen Catalytic Heater
}

\author{
Terry Johnson and Michael Kanouff \\ Thermal/Fluids Science and Engineering 8365 \\ Sandia National Laboratories \\ P.O. Box 969 \\ Livermore, CA 94551
}

\begin{abstract}
This report describes the performance of a high efficiency, compact heater that uses the catalytic oxidation of hydrogen to provide heat to the GM Hydrogen Storage Demonstration System. The heater was designed to transfer up to $30 \mathrm{~kW}$ of heat from the catalytic reaction to a circulating heat transfer fluid. The fluid then transfers the heat to one or more of the four hydrogen storage modules that make up the Demonstration System to drive off the chemically bound hydrogen.

The heater consists of three main parts: 1) the reactor, 2) the gas heat recuperator, and 3) oil and gas flow distribution manifolds. The reactor and recuperator are integrated, compact, finnedplate heat exchangers to maximize heat transfer efficiency and minimize mass and volume. Detailed, three-dimensional, multi-physics computational models were used to design and optimize the system.

At full power the heater was able to catalytically combust a $10 \%$ hydrogen/air mixture flowing at over 80 cubic feet per minute and transfer $30 \mathrm{~kW}$ of heat to a 30 gallon per minute flow of oil over a temperature range from $100{ }^{\circ} \mathrm{C}$ to $220^{\circ} \mathrm{C}$. The total efficiency of the catalytic heater, defined as the heat transferred to the oil divided by the inlet hydrogen chemical energy, was characterized and methods for improvement were investigated.
\end{abstract}




\section{ACKNOWLEDGMENTS}

The authors would like to acknowledge the work of a number of individuals that contributed to this project. The catalyst coating was initially suggested by Tim Shepodd and further developed by LeRoy Whinnery and April Nissen who coated the reactor with help from Pat Keifer. The design of the system was performed with the help of Yon Perras and Sal Birtola. Finally, integration with test apparatus, balance of plant, data acquisition and controls was carried out by Yon Perras, Mark Zimmerman and George Sartor. 


\section{CONTENTS}

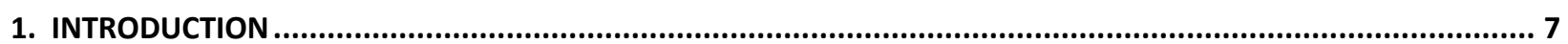

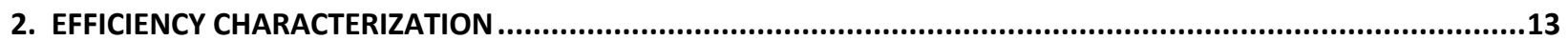

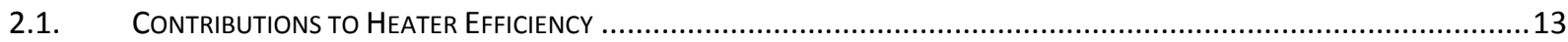

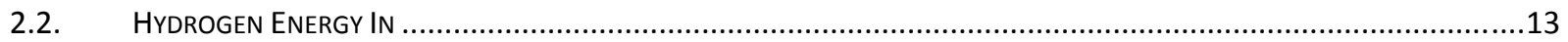

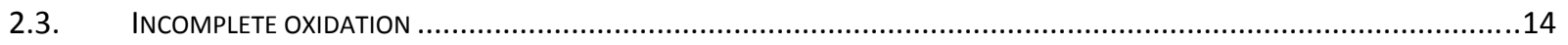

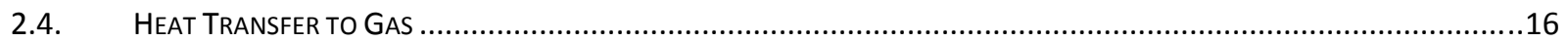

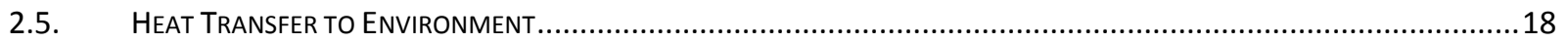

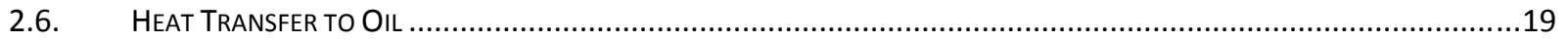

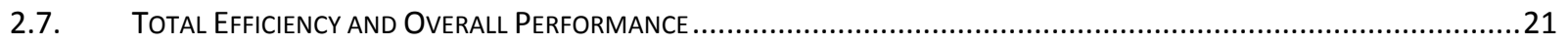

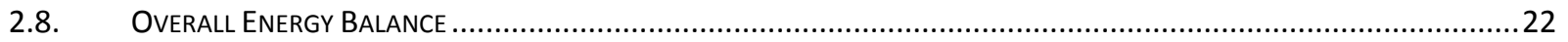

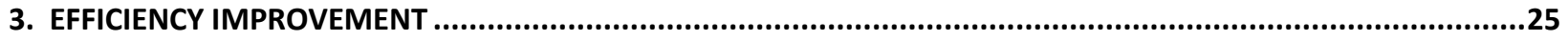

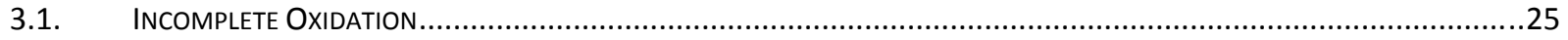

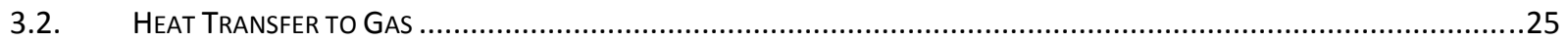

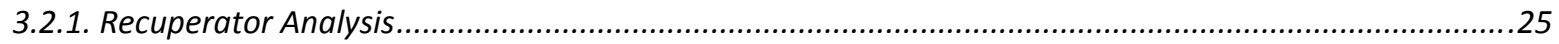

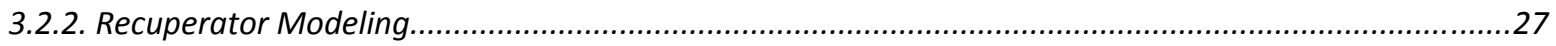

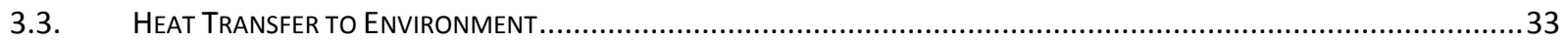

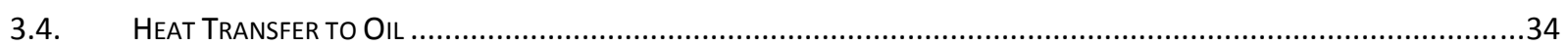

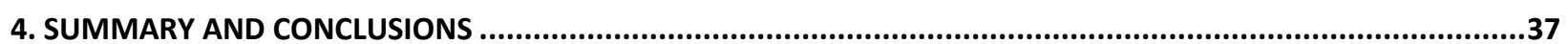

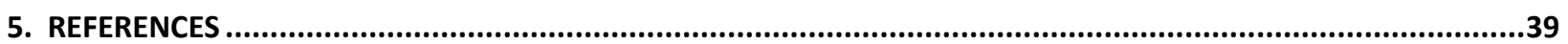

\section{FIGURES}

Figure 1: $30 \mathrm{~kW}$ catalytic heater reactor (left) and recuperator (right)................................... 8

Figure 2: Fully integrated $30 \mathrm{~kW}$ Catalytic Heater.......................................................... 9

Figure 3: Heat distribution as a function of power level using gas flow rate with constant $10 \%$ hydrogen concentration. $30 \mathrm{gpm}$ oil flow rate at $100{ }^{\circ} \mathrm{C}$ and $150{ }^{\circ} \mathrm{C}$. ................................... 10 Figure 4: Neodym ProtiSen hydrogen sensor (a). Corrected sensor output compared to the hydrogen flow controller (b) ........................................................................................... 15 Figure 5: The hydrogen conversion efficiency as a function of mole fraction with a constant feed gas flow rate of $80 \mathrm{cfm}(\mathrm{a})$, and as a function of hydrogen flow rate with a constant $10 \%$

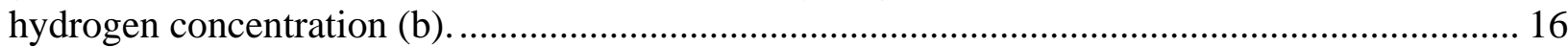

Figure 6: The energy loss to the gas, normalized by the inlet hydrogen chemical energy, as a function of mole fraction with a constant feed gas flow rate of $80 \mathrm{cfm}$ (a), and as a function of hydrogen flow rate for $10 \%$ hydrogen concentration and a 30 gpm flow rate (b)..................... 17

Figure 7: The energy loss to the environment as a function of the heater temperature............... 19 Figure 8. Comparison of measured oil specific heat (left) and density (right) with published

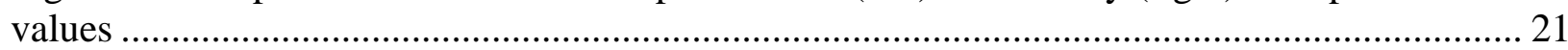
Figure 9. System efficiency as a function of the hydrogen mole fraction with a constant feed gas flow rate of $80 \mathrm{cfm}(\mathrm{a})$, and as a function of hydrogen flow rate for $10 \%$ hydrogen in the feed gas and a 30 gpm oil flow rate (b)............................................................................................. 22 
Figure 10: The overall energy balance as a function of the hydrogen mole fraction with a constant feed gas flow rate of $80 \mathrm{cfm}$ (a), and as a function of hydrogen flow rate for $10 \%$ hydrogen concentration with a $30 \mathrm{gpm}$ flow rate (b) ......................................................... 23

Figure 11: Recuperator temperatures used for performance calculations ................................ 25 Figure 12. Heat flow in recuperator (left) and associated recuperator efficiency (right) for cases

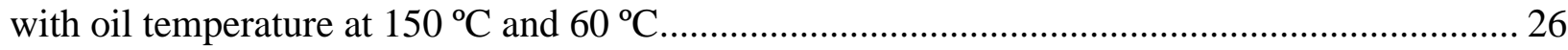
Figure 13: The thermal/fluid finite element model of the recuperator. The portion of the model representing the aluminum (a). The model where the gas domains are also shown (b). 28 Figure 14: A cut-away of the model showing the thermal and fluid velocity fields in the recuperator. 29

Figure 15: The predicted temperature distribution in the recuperator.................................... 30

Figure 16: The predicted temperature profiles in the recuperator. ......................................... 31

Figure 17: Predicted temperature profiles in the recuperator showing the fin effectiveness........ 32

\section{TABLES}

Table 1: Comparison of hydrogen flow rate measurements ................................................. 14

Table 2: Comparison of Recuperator Model to Experimental Results ....................................... 30 Table 3: Predicted efficiencies and pressure drops (psi) in the recuperator for various design parameters ( ${ }^{*}$ as-built parameters) 


\section{INTRODUCTION}

An advanced hydrogen storage system has been developed and demonstrated at Sandia National Laboratories for General Motors [1-3]. The storage system, designed to demonstrate technology needed for fuel cell vehicles, was based on the complex metal hydride, sodium alanate. Like all such materials, heat must be added in order to release hydrogen from sodium alanates. Since sodium alanate release hydrogen at temperatures well above the operating temperature of vehicle fuel cells, a heater was required as part of the hydrogen storage system design. Energy used for heating requires more fuel to be stored on the vehicle or a reduction of the vehicle driving range, so a high efficiency heater was desired.

This report describes the performance of a high efficiency, compact heater that uses the catalytic oxidation of hydrogen to provide heat to the GM Hydrogen Storage Demonstration System. The heater was designed to transfer up to $30 \mathrm{~kW}$ of heat from the catalytic reaction to a circulating heat transfer fluid. The fluid, a synthetic mineral oil, then transfers the heat to one or more of the four hydrogen storage modules that make up the demonstration system.

The catalytic heater produces heat by oxidizing hydrogen as described by the chemical equation,

$$
\mathrm{H}_{2}+1 / 2 \mathrm{O}_{2} \rightarrow \mathrm{H}_{2} \mathrm{O},
$$

Equation 1

which is an exothermic reaction producing about $242 \mathrm{~kJ}$ per mole of $\mathrm{H}_{2}$, assuming $\mathrm{H}_{2} \mathrm{O}$ is in the vapor phase. This reaction occurs in the gas phase only at high temperatures (above $1000{ }^{\circ} \mathrm{C}$ ). At lower temperatures a catalyst is required to promote the oxidation process, i.e. the reaction takes place on the surface of a precious metal, e.g. palladium. Consequently, in order to oxidize hydrogen without producing excessively high temperatures, the heater described here is based on flowing a mixture of hydrogen and air through a large number of catalyst coated channels.

The catalyst coating used with the catalytic heater was developed for ease of application, durability, and reactivity. The coating, developed at Sandia, consists of a carbon-supported palladium powder mixed with a high temperature paint and lacquer thinner. The Pd/carbon powder is commercially available in varying Pd concentrations and consists of Pd clusters on the nanometer scale embedded in carbon particles with diameters in the tens of microns. This powder is mixed with a commercially available furnace paint rated for high temperature. The mixture is then diluted with lacquer thinner to get an appropriate viscosity, applied by dip coating, and cured. The result is a catalyst coating method that is low cost, simple, and produces a highly reactive yet durable coating. This catalyst showed high hydrogen conversion efficiency with no sign of degradation over a 40 hour test period and could not be removed from samples even with industrial solvents.

One of the design issues encountered during the development of the catalytic heater was the energy lost to hot exhaust gases. That is, the mixture of hydrogen and air fed to the reactor is heated by the catalytic reaction removing energy that would otherwise be transferred to the oil. When the hot gas exits the reactor, this energy is lost. Two concepts were incorporated into the catalytic heater design to mitigate this effect. The first was to minimize excess gas flow. From 
an efficiency standpoint, the ideal gas mixture to feed the reactor is a combination of hydrogen and oxygen in stoichiometric proportions (i.e. 2 parts $\mathrm{H}_{2}$ plus 1 part $\mathrm{O}_{2}$, on a molar basis). This would eliminate extraneous gases (e.g. nitrogen) that do not contribute to the exothermic chemical reaction producing useful heat. Unfortunately, such a gas mixture is not practical because pure oxygen is not readily available. The next best solution is a combination of hydrogen and air that is stoichiometric in terms of the hydrogen/oxygen ratio (i.e. 2 parts $\mathrm{H}_{2}, 1$ part $\mathrm{O}_{2}$ and 3.76 parts $\mathrm{N}_{2}$ ). This mixture minimizes the inert gas component, but the hydrogen to air ratio of $30 \%$ is within the explosive limits of hydrogen where a spark could initiate an explosion in the gas. For safety, we chose to operate the cataltyic heater with a maximum hydrogen concentration of $10 \%$ which is well below the lower explosive limit of $18 \%$.

The second design concept was to include a heat exchanger, or recuperator, to transfer heat from the hot exhaust gas to pre-heat the cool feed gas. That is, although the amount of hot exhaust gas can be minimized as described above, the use of air (which includes $79 \%$ nitrogen) and a maximum of $10 \%$ hydrogen for the feed gas still ensures that a large amount of hot exhaust gas will be created. A recuperator to transfer that heat to the feed gas was incorporated into the catalytic heater design to improve its thermal efficiency.

The design of the catalytic heater consisted of three main parts: 1) the reactor, 2) the gas heat recuperator, and 3) oil and gas flow distribution manifolds. The reactor consisted of a brazed aluminum assembly of ten alternating layers of finned channels for gas and oil flow. The gas heat recuperator was designed to maximize heat exchange with minimum pressure drop and size. A three layer finned plate design was used for this purpose. The recuperator was tightly integrated with the reactor to minimize the overall footprint and acted as a cover for one end of the reactor gas channels. These components are shown in Figure 1.

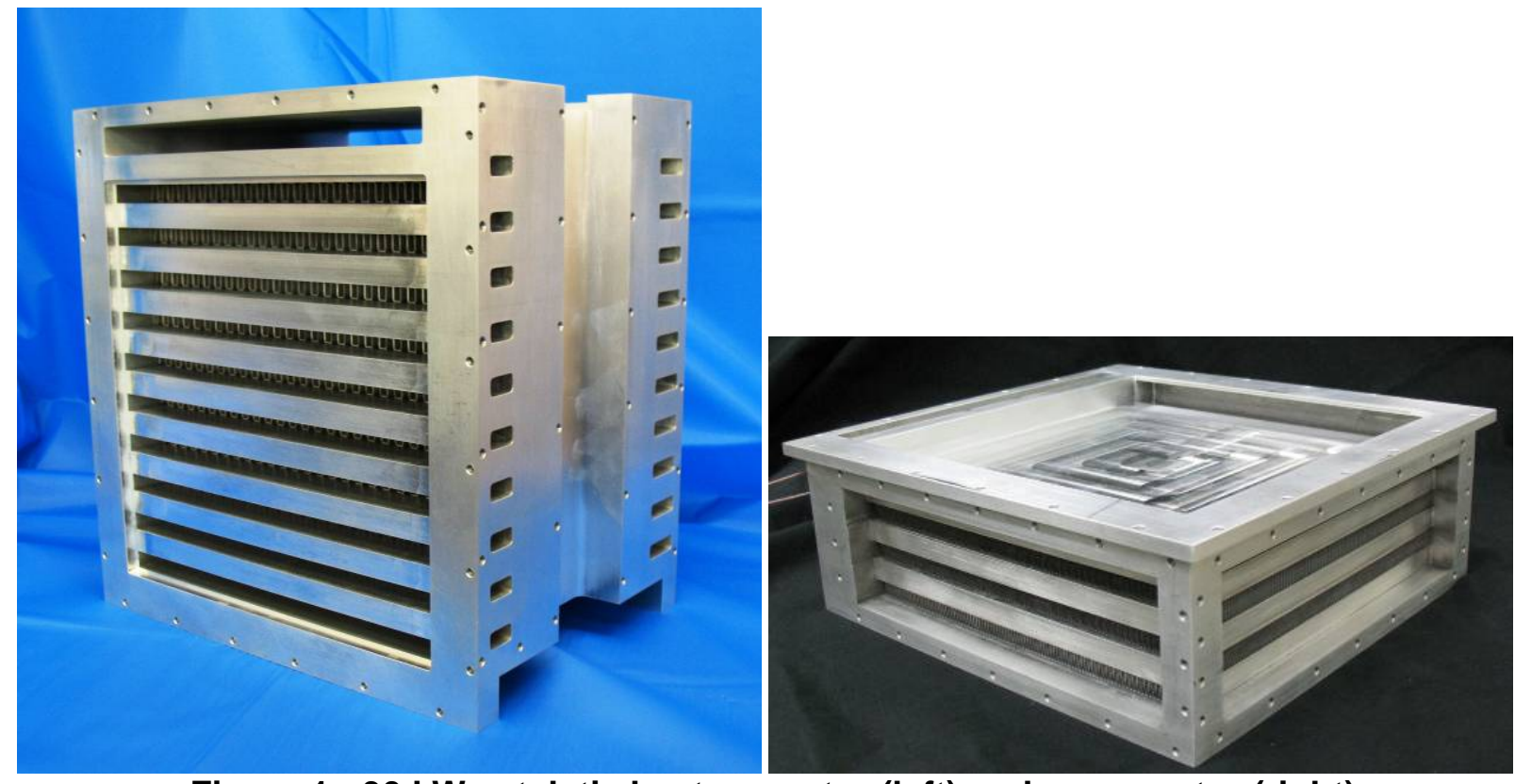

Figure 1: $30 \mathrm{~kW}$ catalytic heater reactor (left) and recuperator (right).

The oil and gas flow distribution scheme was a particularly challenging part of the system design. The challenge was to split a single gas or oil stream into several hundred to several 
thousand streams with uniform flow rates. Uniformity was required to spread the heat generation and heat transfer throughout the entire heater volume to minimize hot spots and maximize hydrogen conversion and heat transfer efficiency. The general solution was to use large manifold plenums to lower flow rates and limit dynamic pressure gradients. In addition, flow diffusers in the form of aluminum foam plates were used to further improve uniformity at key locations.

The resulting heater assembly was instrumented and integrated with the Demonstration System test facility for performance evaluation and use with the hydrogen storage system. The integrated system is shown in Figure 2 prior to the addition of insulation panels. The outer envelope of the heater is 15.0 ” X 12.6" X 11.7" not including the air blower or oil pump that would be required to run the system. At full power the heater was able to catalytically combust a $10 \%$ hydrogen/air mixture flowing at over 80 cubic feet per minute and transfer $30 \mathrm{~kW}$ of heat to a 30 gallon per minute flow of oil. Over a temperature range from $100{ }^{\circ} \mathrm{C}$ to $220^{\circ} \mathrm{C}$, the total efficiency of the catalytic heater was better than $75 \%$. When operated as the heat source for hydrogen delivery from the hydrogen storage system, the catalytic heater allowed for the dynamic control of the temperatures of multiple storage modules in order to meet the demands of real world fuel cell drive cycles.

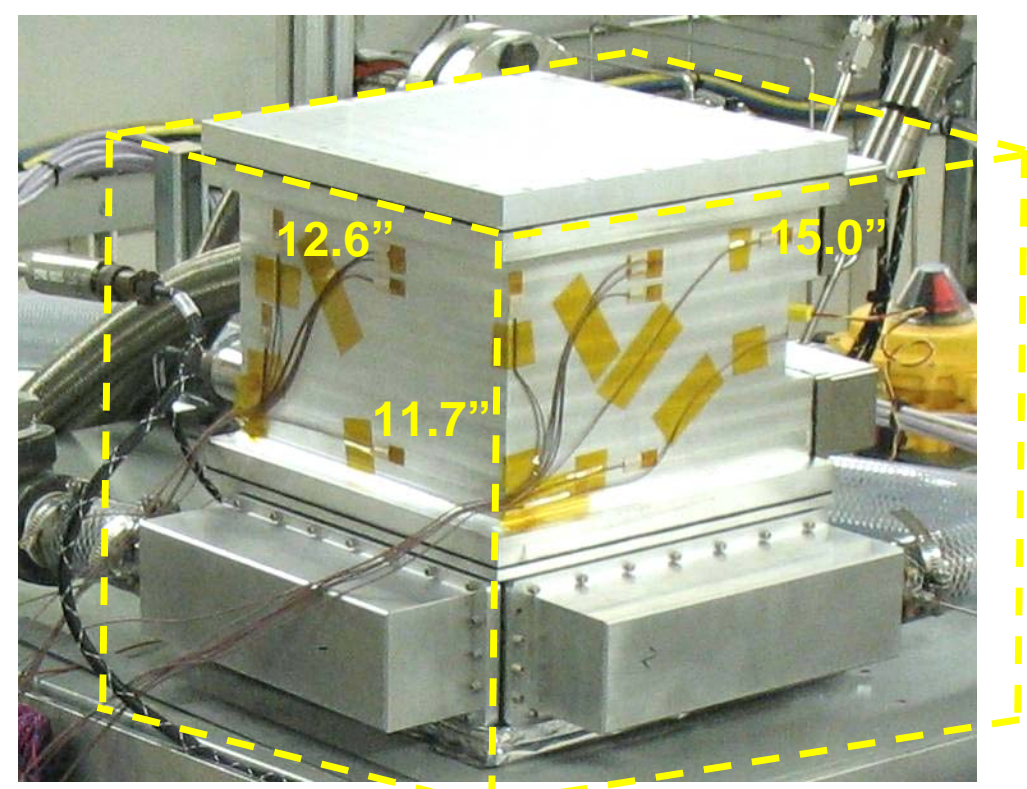

Figure 2: Fully integrated 30 kW Catalytic Heater

Although good performance was demonstrated with the catalytic heater, data obtained during the GM project left questions as to the absolute efficiency of the heater and sources of efficiency loss. Figure 3 shows a breakdown of heat flow as the heater power is varied from $20 \%$ up to $100 \%$ by controlling total gas flow with a constant $10 \%$ hydrogen concentration. The individual heat flow contributions are calculated based on various temperature, fluid flow, and species concentration measurements. Reaction heat is based on the measured difference between the hydrogen mass flow entering the heater and that which exits the heater. Heat transferred to the 
oil is based on measured oil flow rate and inlet and outlet temperatures. Similarly, heat transferred to the gas is based on measured gas flow rate and inlet and outlet temperatures. The environmental heat loss value is calculated from the other quantities, it was not directly measured.

Figure 3 presents the energy flows in steady state operation as a function of power level. The data shows that the reaction heat varies nearly linearly with the inlet hydrogen flow rate, or equivalently, the power level. The reaction heat is slightly higher at $150{ }^{\circ} \mathrm{C}$ than at $100{ }^{\circ} \mathrm{C}$ due to the difference in hydrogen conversion efficiency; more hydrogen is consumed by the catalytic reaction at the higher temperature. The heat transferred to the oil is higher at $100{ }^{\circ} \mathrm{C}$ than at 150 ${ }^{\circ} \mathrm{C}$ due to higher losses to gas heating and to the environment at the higher temperature. Losses to gas heating are estimated at about $10 \%$ of the reaction heat at $150{ }^{\circ} \mathrm{C}$. Environmental losses appear to be even higher than gas heating losses, especially at $150{ }^{\circ} \mathrm{C}$ where the environmental loss reaches $15 \%$ of the reaction heat.

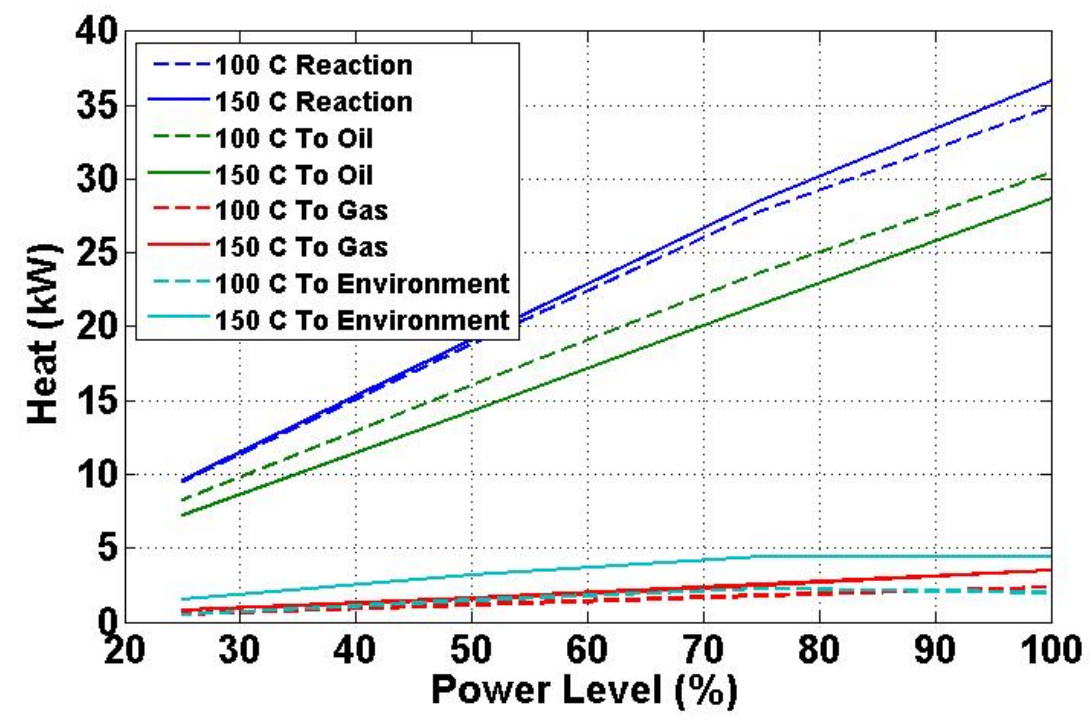

Figure 3: Heat distribution as a function of power level using gas flow rate with constant $10 \%$ hydrogen concentration. $30 \mathrm{gpm}$ oil flow rate at $100^{\circ} \mathrm{C}$ and $150{ }^{\circ} \mathrm{C}$.

It is this environmental heat loss value that raises questions as to the validity of the data. The value is unexpectedly high considering that the catalytic heater is very well insulated and has a compact size. Also, the large variation in the environmental loss term as a function of heater power ( $2 \mathrm{~kW}$ to almost $5 \mathrm{~kW}$ ) would not be expected since the overall temperature of the heater does not change significantly. Since the environmental heat loss value is calculated from the other quantities and not directly measured, this behavior may indicate an error in one or more of the other heat terms. This report will describe a detailed investigation of these possible errors in an attempt to better quantify the performance of the catalytic heater and identify areas for improvement. All of the measured quantities used to calculate energy into or out of the catalytic heater were characterized and, where possible, were compared to redundant measurements. Corrections to some heat flow calculations were made based on this investigation and a revised efficiency estimate was assembled. 
In addition to the efficiency characterization of the catalytic heater, some design aspects were investigated to improve efficiency. For example, the $10 \%$ loss to gas heating for the catalytic heater was higher than expected. A small-scale prototype had demonstrated a 3\% loss to gas heating by using a recuperator with an efficiency of about $80 \%$. The recuperator designed for the $30 \mathrm{~kW}$ heater was predicted to have an efficiency of $75 \%$, which would have resulted in a loss slightly higher than $3 \%$, but not nearly as high as $10 \%$. So, the recuperator may not have achieved the heat recovery that was predicted. An analysis of the recuperator performance using a detailed computational model was carried out, and results will be compared to data from the catalytic heater. In addition, the model was used to predict the performance of modified recuperator designs in an effort to improve overall heater efficiency. A comparison of these designs with the original will be discussed.

Other performance improvements were considered as well. A discussion of the potential impact of improved hydrogen conversion, better insulation, and more uniform flow will also be presented. 



\section{EFFICIENCY CHARACTERIZATION}

\subsection{Contributions to Heater Efficiency}

Efficiency is a key performance characteristic for the catalytic heater, as it is for any energy system. Here efficiency is defined as the fraction of the chemical energy in the hydrogen feed gas that is transferred to the oil in the form of heat. Not all of the available energy is transferred to the oil. Some energy is lost. Identifying and quantifying sources of this energy loss was the focus of the first part of this work so that methods of improving the overall efficiency could be identified. Three main loss mechanisms were identified: 1 ) incomplete oxidation of the hydrogen, 2) heat losses to the exhaust gases, and 3) heat losses to the environment. The methods used to quantify the total energy efficiency and energy loss mechanisms are described below.

\subsection{Hydrogen Energy In}

The chemical energy in the hydrogen feed gas is given by $\dot{n}_{H 2}^{i n} * \Delta \mathrm{H}_{\mathrm{H} 2}$ where $\dot{n}_{H 2}^{i n}(\mathrm{~mol} / \mathrm{s})$ is the inlet hydrogen flow rate and $\Delta \mathrm{H}_{\mathrm{H} 2}$ is the enthalpy of reaction of hydrogen and oxygen (forming water vapor as the product of reaction). Quantifying this energy is the first step towards evaluating the system efficiency. The hydrogen molar flow rate is obtained by dividing the mass flow rate, $\dot{m}_{H 2}$, by the molecular weight of hydrogen. The mass flow rate was measured using a Brooks model SLA5851D mass flow controller calibrated for hydrogen flow up to 10 standard cubic feet per minute $(\mathrm{scfm})$. The maximum design flow rate for the catalytic heater was $8 \mathrm{scfm}$ $(0.31 \mathrm{~g} / \mathrm{sec})$ of hydrogen which, if fully reacted, would produce $37.2 \mathrm{~kW}$ of heat. The flow controller was factory calibrated with an inlet pressure of $50 \mathrm{psi}$ and an outlet pressure of $10 \mathrm{psi}$ at $70^{\circ} \mathrm{F}$. The reported accuracy of the unit was better than $\pm 1 \%$ of the flow rate.

An error in the hydrogen flow rate measurement contributes directly to an error in heater efficiency as well as an error in the overall system energy balance. Thus, reported heater efficiencies are at best subject to the accuracy of the hydrogen flow controller. According to the manufacturer's specifications, this error should be $\pm 1 \%$. However, during operation the flow controller was found to be quite sensitive to pressure and temperature of the inlet hydrogen. To characterize the performance of the flow controller, it was compared to another flow measurement device: an Emerson Micro Motion Elite CMF010 flow meter. This meter was used to measure desorption rates of the hydrogen storage system and is capable of flow measurements up to $1.5 \mathrm{~g} / \mathrm{sec}$ with an error of less than $\pm 0.35 \%$ of the reading. The Emerson flow meter uses a direct mass flow measurement based on the Coriolis effect in vibrating curved tubes. Because it measures mass directly, this flow meter is largely unaffected by temperature and pressure.

By measuring hydrogen flow through the Emerson flow meter and the Brooks flow controller simultaneously, a comparison was made of the two flow measurements. Because of the superior accuracy of the Emerson device, it was used as a standard for calibrating the flow controller. Table 1 shows hydrogen flow measurements of the Brooks flow controller compared to the Emerson flow meter measurements. The table shows that over a range of heater power levels from $38 \%$ to $100 \%$, the Brooks flow controller consistently over-estimated the hydrogen flow 
rate. Based on the Emerson flow meter, the actual flow rate was 91\% to 93\% of the Brooks value.

Table 1: Comparison of hydrogen flow rate measurements

\begin{tabular}{|c|c|c|}
\hline $\begin{array}{c}\text { Brooks flow } \\
\text { controller } \\
\text { (g/sec) }\end{array}$ & $\begin{array}{c}\text { Emerson } \\
\text { flow meter } \\
\text { (g/sec) }\end{array}$ & Ratio \\
\hline 0.120 & 0.112 & 0.933 \\
\hline 0.160 & 0.146 & 0.913 \\
\hline 0.240 & 0.221 & 0.921 \\
\hline 0.310 & 0.288 & 0.929 \\
\hline
\end{tabular}

This error partially explains the high environmental loss values that were calculated as the difference between the reaction heat and the heat transferred to the gas and oil. At $150^{\circ} \mathrm{C}$, the hydrogen conversion is nearly $100 \%$, so nearly all of the energy in the hydrogen entering the heater is converted to heat. At full power, the energy difference between a hydrogen flow rate of $0.31 \mathrm{~g} / \mathrm{sec}$ and $0.288 \mathrm{~g} / \mathrm{sec}$ is $2.64 \mathrm{~kW}$. This accounts for more than half of the $5 \mathrm{~kW}$ of environmental loss that was calculated for this case. The Brooks flow controller error will be taken into account when total efficiency of the catalytic heater is discussed in a later section.

\subsection{Incomplete oxidation}

Some of the inlet hydrogen chemical energy is lost due to incomplete oxidation, where the unreacted hydrogen is convected out of the heater by the exhaust gases. The amount of un-reacted hydrogen was quantified by measuring the mole fraction of hydrogen in the exhaust gases, $\mathrm{x}_{\mathrm{H} 2}$. Determination of the outlet hydrogen molar flow rate also requires the total molar flow rate of the exhaust gases. This value is different than the inlet total molar flow rate because the reaction described by Eqn. 1 shows that one and a half moles of reactant gases are consumed for each mole of product gas produced. Taking this effect into account, the outlet hydrogen flow rate is given by,

$$
\dot{n}_{H 2}^{\text {out }}=\frac{X_{H 2}\left(\dot{n}_{\text {air }}^{\text {in }}+\frac{1}{2} \dot{n}_{H 2}^{\text {in }}\right)}{1-\frac{1}{2} X_{H 2}},
$$

Equation 2

where $\dot{n}_{a i r}^{\text {in }}$ is the inlet air molar flow rate.

To measure $\mathrm{x}_{\mathrm{H} 2}$, we used the Neodym ProtiSen catalytic $\mathrm{H}_{2}$ sensor shown in Figure 4a. The specifications for this sensor matched the response and sensitivity we needed. It could detect hydrogen in a range from 0 to $4 \%$ with a 3 second response time and 10 second recovery time. The sensor would operate at temperatures up to $80{ }^{\circ} \mathrm{C}$ in gas with $99 \%$ relative humidity. The reported accuracy was $\pm 6.5 \%$ in a flowing gas stream.

We purchased and tested a ProtiSen sensor. While the response time was near the reported spec, we found it to be less accurate than promised. However, the response was repeatable and we were able to add a calibration correction using our hydrogen flow controller as a standard. The 
resulting response is shown in Figure 4b. Hydrogen concentration is varied using the flow controller shown in blue and the corrected Neodym sensor output is shown in red. Within 10 seconds the Neodym sensor reaches about $95 \%$ of the flow controller value. Based on these results, the sensor was used to characterize hydrogen conversion efficiency of the catalytic heater.
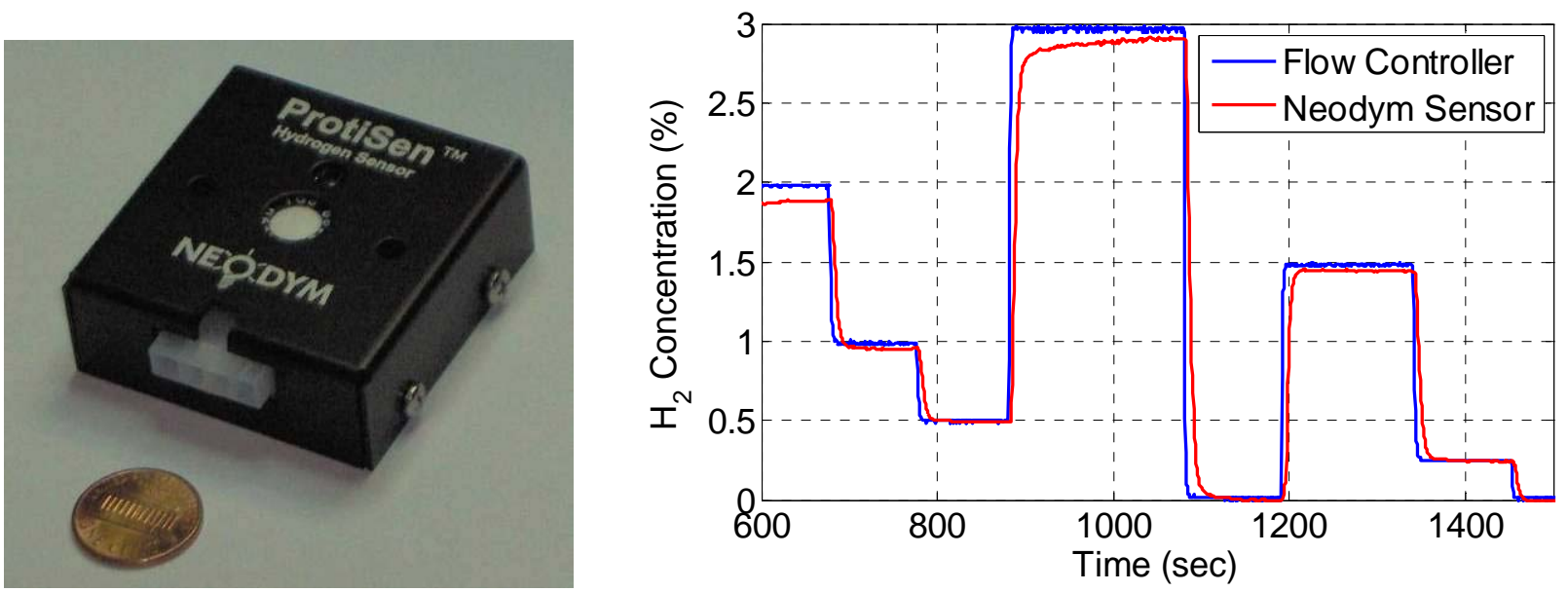

Figure 4: Neodym ProtiSen hydrogen sensor (a). Corrected sensor output compared to the hydrogen flow controller (b).

The results for the amount of un-reacted hydrogen are normalized by the amount of hydrogen in the feed gas. This ratio is referred to here as the hydrogen conversion efficiency. Figure 5a shows the conversion efficiency for a range of inlet oil temperatures and flow rates, as a function of the hydrogen mole fraction of the feed gas. The feed gas flow rate is kept constant at $80 \mathrm{cfm}$, while the ratio of hydrogen to air is varied. The conversion efficiency increases with the oil temperature and the hydrogen mole fraction, both of which result in an increase in the overall heater temperature. Higher temperatures result in faster chemical kinetic rates because the oxidation reaction is thermally activated. Similarly, a slower oil flow rate results in less cooling of the heater, and higher heater temperatures, which also leads to larger conversion efficiencies. Note that the conversion efficiencies resulting from low inlet oil temperatures are significantly below unity, while those for high oil temperatures approach unity (complete conversion).

Figure 5b shows the effect of oil temperature on conversion efficiency as a function of the hydrogen flow rate in the feed gas where the hydrogen mole fraction is kept constant at $10 \%$. The oil flow rate is 30 gpm in all cases. Note that in both Fig. 5a and Fig. 5b the hydrogen flow rate in the feed gas increases from left to right. Interestingly, the conversion efficiency increases with hydrogen flow rate in Fig. 5a, while it decreases with hydrogen flow rate in Fig. 5b. The increase seen in Fig. 5a is apparently due to the increase in temperature of the heater as discussed above. The decrease in conversion efficiency with hydrogen flow rate seen in Fig. 5b appears to be due to a decrease in residence time of the hydrogen in the heater. That is, because the total gas flow rate increases, the gas velocity increases resulting in a decrease of the residence time. Note that the heater temperature increases with hydrogen flow rate when the hydrogen mole fraction is kept constant at $10 \%$, but this affect appears to be offset by the residence time affect. In any case, for a given oil temperature and oil flow rate the conversion efficiency is larger when the hydrogen mole fraction in the feed gas is kept constant at $10 \%$. 

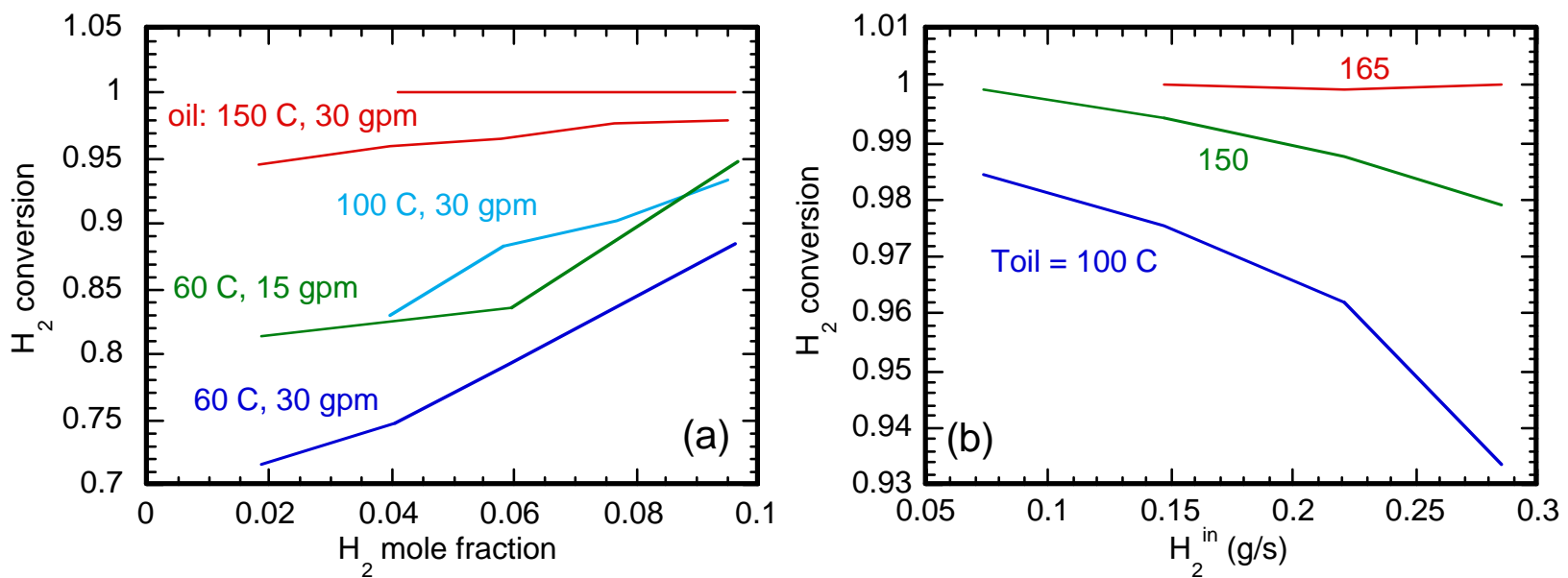

Figure 5: The hydrogen conversion efficiency as a function of mole fraction with a constant feed gas flow rate of $80 \mathrm{cfm}(\mathrm{a})$, and as a function of hydrogen flow rate with a constant $10 \%$ hydrogen concentration (b).

Based on Figure $5 \mathrm{~b}$, at temperatures above $100^{\circ} \mathrm{C}$, very little hydrogen is left in the exhaust gas. This is especially true when the catalytic heater is operated in the preferred mode with a constant $10 \%$ hydrogen inlet concentration. For these conditions, the Neodym sensor measurements show that less than $7 \%$ of the inlet hydrogen remains in the exhaust gas. At the highest power level, this equates to a loss of $2.42 \mathrm{~kW}$ of energy. Errors in this measurement introduced by calibration with the Brooks flow controller and those intrinsic to the device might be as high as $15 \%$ combined. However, that amounts to just $363 \mathrm{~W}$ which is in the noise of the rest of our measurements. In other words, measurement errors in the outlet hydrogen flow rate have a minimal effect on the calculation of total efficiency or the overall energy balance.

\subsection{Heat Transfer to Gas}

Energy is lost to the gas by heat transfer from the hot catalytic surfaces to the gas flowing through the reactor, and then the convective transport of that heat by the gas out of the reactor through the recuperator in the form of hot exhaust gases. This energy loss was evaluated based on the mass flow rate of the gas and measured gas temperatures at the inlet and outlet to the recuperator, as given by,

$$
\Delta E_{\text {gas }}=\dot{m}_{\text {total }}\left\lfloor\left(c_{p} T\right)_{\text {out }}-\left(c_{p} T\right)_{\text {in }}\right\rfloor
$$

Equation 3

where $\dot{m}_{\text {total }}$ is the sum of the mass flow rates of inlet air and hydrogen. The specific heats of the inlet and outlet gas mixtures were evaluated using weighted averages of each gas species present in each gas stream. The hydrogen mass flow rate was measured by the Brooks flow controller, but corrected based on the calibration with the Emerson flow meter as previously discussed.

The air flow to the catalytic heater was produced by a single stage regenerative blower; model HRB300 from Republic Sales and Manufacturing. This blower was rated for $80 \mathrm{scfm}$ air flow at a pressure of 2.5 psi. To achieve $30 \mathrm{~kW}$ of heat output from the catalytic heater, the blower would need to produce $72 \mathrm{scfm}$. A large diameter exhaust line was installed to limit the air 
pressure drop so that this flow rate could be achieved. The blower was controlled using an Allen Bradley PowerFlex 40 variable frequency drive (VFD). The drive was configured to operate the blower with a PID control loop using measured air flow rate as the feedback. The air flow rate was measured by an FTB-938 gas turbine flow meter from Omega. This flow meter was factory calibrated and coupled with a transmitter to provide a $4-20 \mathrm{~mA}$ signal for air flow rates from 0 to $143.1 \mathrm{scfm}$. The specified accuracy of this flow meter is $\pm 1 \%$.

The inlet and outlet gas temperatures were measured with K-type thermocouples that were mounted to the inlet and outlet gas manifold covers. These thermocouples were installed such that the probe tips were centered in the gas flow stream. Errors in temperature from thermocouple measurements are typically $\pm 1^{\circ} \mathrm{C}$. All of the thermocouples used on the catalytic heater were calibrated from their connectors back to the data acquisition system (DAQ) using a Fluke 724 Temperature Calibrator. This ensured that temperature errors were limited to the thermocouples themselves.

Figure 6 shows heat loss to the gas calculated using the measurements just discussed. The heat loss is shown in the figure as a fraction of the inlet hydrogen energy to show it as an efficiency loss. In general, the energy loss to the gas increases as the heater temperature increases because this results in higher exhaust gas temperatures despite the recuperator. The heater temperature increases with the oil temperature and heater power.

Figure 6a shows the effect of oil temperature and flow rate on the loss as a function of the hydrogen mole fraction. The total gas flow rate was kept constant at $80 \mathrm{cfm}$. The loss to the gas is primarily affected by the inlet oil temperature, where large temperatures result in significant losses, especially if the feed gas has a low hydrogen mole fraction. Note that the two sets of data at $150{ }^{\circ} \mathrm{C}$ are nearly identical as are the sets at $60^{\circ} \mathrm{C}$ despite the different oil flow rates. The decrease in the normalized energy loss to the gas with mole fraction (for $150^{\circ} \mathrm{C}$ oil) shows the benefit of using large hydrogen concentrations where excess gas flow is minimized.
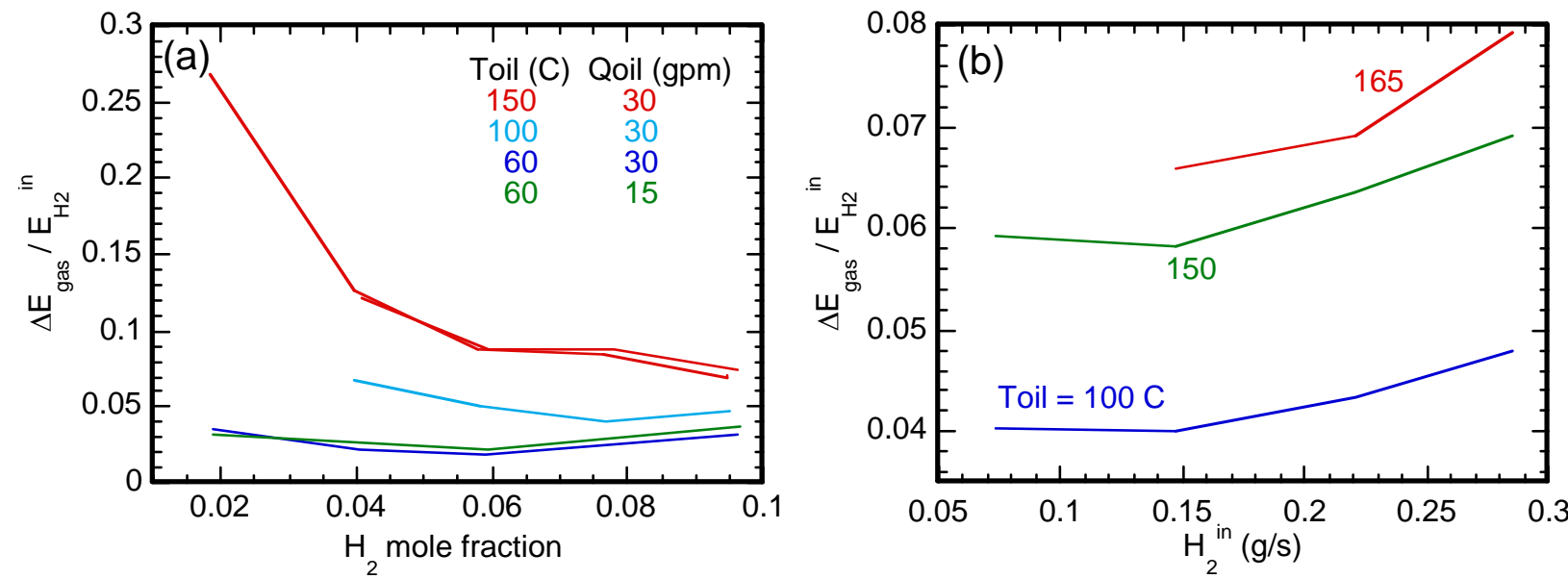

Figure 6: The energy loss to the gas, normalized by the inlet hydrogen chemical energy, as a function of mole fraction with a constant feed gas flow rate of $80 \mathrm{cfm}(\mathrm{a})$, and as a function of hydrogen flow rate for $\mathbf{1 0 \%}$ hydrogen concentration and a $\mathbf{3 0} \mathrm{gpm}$ flow rate

(b). 
Figure $6 \mathrm{~b}$ shows the effect of oil temperature on the energy loss to the gas as a function of the hydrogen flow rate in the feed gas where the hydrogen mole fraction is kept constant at $10 \%$. The oil flow rate is $30 \mathrm{gpm}$ in all cases. Since the hydrogen concentration in the feed gas is constant, the total gas flow rate increases with the increase in hydrogen flow rate. This increased flow rate along with the higher temperatures produced are what contribute to the increase in heat loss from low to high hydrogen flow rate.

The heat lost to the exhaust gas of the catalytic heater reaches $7 \%$ of the total energy at full power and $150^{\circ} \mathrm{C}$. Note that this value is lower than the $10 \%$ found previously. The difference is due to the more rigorous analysis of the data. Corrections to the mass flow rate and the average specific heat calculations resulted in a more exact and lower result. However, this value is still higher than had been hoped for based on the gas heat recuperator design, as will be discussed in a later section.

\subsection{Heat Transfer to Environment}

Energy is lost to the environment by heat conduction through the insulation surrounding the heater, and then from the outer surface of the insulation to the surroundings by natural convection and thermal radiation. The previous method for estimating this energy loss used the difference between the heat generated in the catalytic reactor and the heat transferred to the oil and gas. Because this resulted in what seemed to be an erroneous value, an experiment was designed specifically for estimating the environmental heat loss. First, hot oil was used to raise the temperature of the heater to an elevated value. There was no gas flow in this experiment. Then, the oil flow was stopped and the rate of temperature decrease of the heater was monitored over time. Based on the heat capacity of the heater, including the hardware and stagnant oil it contained, the rate of energy loss was determined from the cooling rate of the heater, as given by,

$$
\dot{E}_{\text {environmert }}=-\sum m c_{p} \frac{d T}{d t}
$$

Equation 4

where the product of mass and specific heat is summed over the hardware and oil in the heater. The temperature of the heater was measured in several locations and under the conditions of this experiment they all were approximately equal.

Figure 7 shows the environmental energy loss, calculated using Equation 4, as a function of the catalytic heater temperature. It is near zero when the temperature is near room value, and it increases with heater temperature, as expected. The nonlinear response of the energy loss with temperature is probably due to the contribution of thermal radiation, but it could also result from natural convection, especially if it is turbulent. The energy loss to the environment exceeds 500 $\mathrm{W}$ for temperatures above $150^{\circ} \mathrm{C}$. However, this is almost an order of magnitude lower than the values estimated previously.

While this calculation of environmental heat loss is an improvement over the previous method, it is certainly not exact. Errors are associated with the estimation of the thermal inertia terms $\left(\mathrm{mc}_{\mathrm{p}}\right)$ as well as treating the catalytic heater with this lumped thermal mass approach. However, it is 
not likely that these errors would be as large as $100 \%$. Thus, the environmental heat loss is certainly less than $1 \mathrm{~kW}$ at $150^{\circ} \mathrm{C}$.

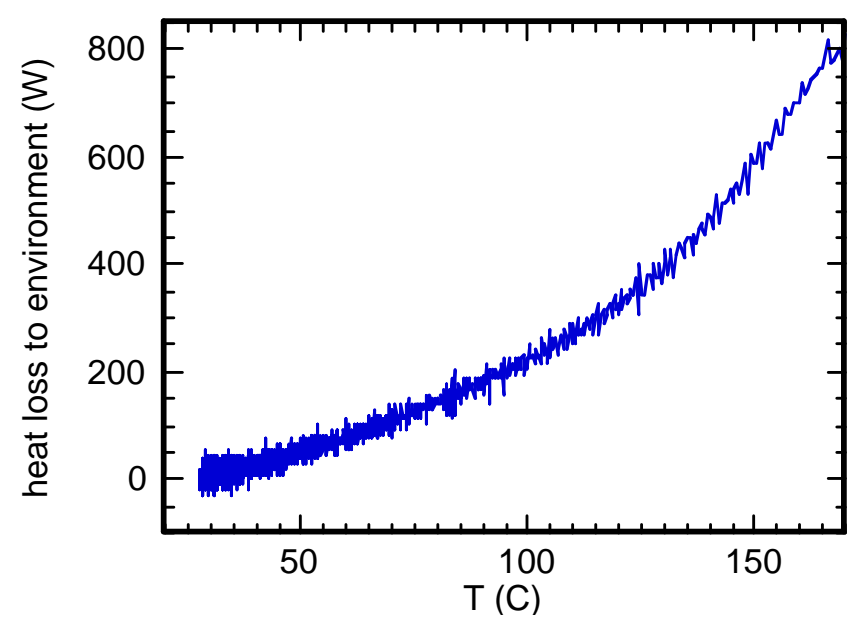

Figure 7: The energy loss to the environment as a function of the heater temperature.

The results of this test validated the hypothesis that previous estimates of environmental heat loss were too high. The temperature dependant value obtained here will be used for calculations of total efficiency and overall energy balance that follow.

\subsection{Heat Transfer to Oil}

Energy is transferred to the oil by heat conduction from the hot catalytic surfaces in the gas flow channels to the oil flow channels, and finally to the oil. The oil then transfers this energy out of the heater by convection. Evaluation of the heat transfer to the oil is based on the oil flow rate and temperature measurements of the outlet and inlet oil. It is given by,

$$
\Delta E_{\text {oil }}=Q_{\text {oil }} \rho_{\text {oil }} \int_{\text {in }}^{\text {out }} c_{p} d T
$$

where $Q_{o i l}$ is the volumetric oil flow rate, $\rho_{\text {oil }}$ is the oil density, and $\mathrm{c}_{\mathrm{p}}$ is the specific heat of the oil. Temperature dependent values of both $\rho_{\text {oil }}$ and $c_{p}$ were used. These were formulated in terms of linear relationships based on property data provided by the manufacturer of the oil (XCELTHERM 600, Radco Industries). Since $Q_{\text {oil }}$ was measured the outlet of the heater, $\rho_{\text {oil }}$ was evaluated at the outlet oil temperature. The integral was used to get an average specific heat of the oil as the temperature changed from inlet to outlet. Using a linear relationship between $\mathrm{c}_{\mathrm{p}}$ and $\mathrm{T}$, the integral reduces to $\mathrm{C}_{0} \mathrm{~T}+\mathrm{C}_{1} \mathrm{~T}^{2} / 2$, where $\mathrm{C}_{0}$ and $\mathrm{C}_{1}$ are constants.

The primary function of the catalytic heater was to transfer as much of the hydrogen energy as possible to the oil stream. So, accurate calculation of this heat transfer was critical to the performance evaluation of the catalytic heater. Also, next to the hydrogen inlet energy, the heat transferred to the oil was the largest contributor to an overall energy balance. Thus, each of the measurements that contributed to this calculation was checked for accuracy. In addition, the oil density and specific heat were measured by a third party to check the manufacturer's data. 
Like the gas temperature measurements, oil inlet and outlet temperatures were measured by thermocouples attached to the inlet and outlet oil manifold covers. These K-type thermocouples were centered in the oil stream and calibrated back to the DAQ. However, while the temperature difference between the gas inlet and outlet streams was large $(\sim 50 \mathrm{C})$ the increase in the oil temperature was less than ten degrees for all heater powers at the nominal flow rate of $30 \mathrm{gpm}$. So, a small temperature error could have a large effect on the oil heat transfer term. For the performance evaluation tests, this effect was minimized by establishing steady state conditions and using relative differences. For instance, oil temperatures would be stabilized at $150{ }^{\circ} \mathrm{C}$ without hydrogen flow so that no heat was produced by the heater. The temperature difference was zeroed at this condition. Then, hydrogen flow would be turned on and temperatures would be allowed to reach steady state again. The temperature difference at this condition relative to that at the zero condition was then used for the heat transfer calculation. In this way, the inaccuracy in the absolute temperatures given by the thermocouples was negated.

In addition to this technique, a redundant oil outlet temperature measurement was made. A thermocouple was mounted several inches downstream of the original outlet temperature sensor and data was collected for comparison. This measurement served two purposes. First, it provided a verification of the original thermocouple measurements. Second, because the location was further from the oil outlet manifold where the stream would be better mixed, this measurement would be less likely to be affected by a temperature gradient in the oil. The results, which will be shown later, matched quite well with the original temperature measurements indicating this was not a source of error.

The oil flow rate was measured using an Endress and Hauser Prowirl 72W vortex flow meter. This meter measures flow rates up to $197 \mathrm{gpm}$ with a reported accuracy of $\pm 0.75 \%$ of reading. The meter came from the factory calibrated to within this accuracy range using water at $25^{\circ} \mathrm{C}$. However, the manufacturer's literature suggests that measurement errors associated with using a different fluid at a different temperature can be several percent. Also, since the nominal oil flow rate through the catalytic heater was $30 \mathrm{gpm}$, non-linearity near the low end of the measurement range could introduce an additional error.

Because an error of less than $10 \%$ in the oil flow rate would result in a heat transfer error of several kilowatts, we decided to verify this measurement. A second oil flow meter was purchased that used a different measurement technique. The Flow Technology (FTI) FT-16 turbine flow meter was capable of measuring flow rates up to $60 \mathrm{gpm}$ at $150{ }^{\circ} \mathrm{C}$. The meter and 4-20mA transmitter were calibrated over a flow range from $5 \mathrm{gpm}$ to $30 \mathrm{gpm}$ at the viscosity of Xceltherm to within $\pm 0.14 \%$ using a NIST traceable standard.

The turbine flow meter was only to be used to validate the vortex flow meter readings, so only a single test was run with this meter. The FTI meter was installed per the manufacturer specifications in series with the existing Prowirl meter. The oil recirculation system was then used to provide a heated oil stream through both meters at several flow rates. The flow was controlled based on the Prowirl meter, but both measurements were captured. Over a range of flow rates from 10 gpm to 30 gpm, the Prowirl values were consistently low by about 5\%. A correction to this error was used in the calculations of oil heat transfer that will be shown below. 
The final components of Equation 3 are the oil density and specific heat. The oil manufacturer, Radco Industries, had provided temperature dependant values, however we felt it was prudent to check these values. An analysis of the heat transfer fluid was provided by Impact Analytical, Midland, MI. The specific heat was measured using a TA Instruments Q100 differential scanning calorimeter under a nitrogen atmosphere following the general procedure detailed in ASTM E1269-01. The instrument gave specific heat values from $20^{\circ} \mathrm{C}$ to $195^{\circ} \mathrm{C}$ in $5{ }^{\circ} \mathrm{C}$ increments. The oil density was measured at five points spanning the range from $20^{\circ} \mathrm{C}$ to 200 ${ }^{\circ} \mathrm{C}$. The results are shown plotted against the Radco data in Figure 8. In both cases, the measured values were just slightly lower than the reported values. At $150{ }^{\circ} \mathrm{C}$, the combined effect would reduce the calculated oil heat transfer by about $3 \%$.
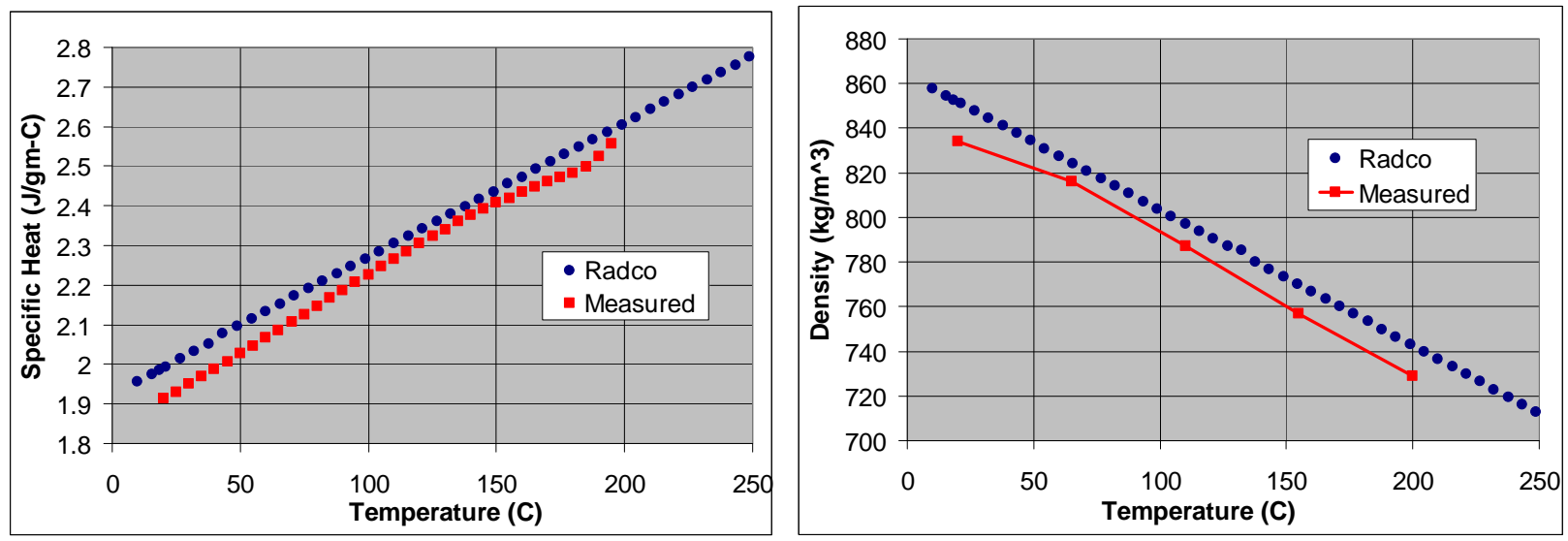

Figure 8. Comparison of measured oil specific heat (left) and density (right) with published values

Results for the energy transfer to the oil are presented in the next section.

\subsection{Total Efficiency and Overall Performance}

The total efficiency of the catalytic heater is calculated as the heat transferred to the oil divided by the total energy available in the incoming hydrogen. Figure 9 shows this value, as with previous figures, as a function of temperature, hydrogen concentration, and total gas flow rate. As a function of temperature, total efficiency is low at low temperature, peaks at medium temperature, and drops at higher temperature. At low temperature, like the $60 \mathrm{C}$ case in Figure 9a, losses are fairly small so total efficiency is primarily driven by hydrogen conversion efficiency. Referring back to Figure 5a, hydrogen conversion efficiency was low at $60^{\circ} \mathrm{C}$, especially at 30 gpm oil flow. At medium temperature, like the $100{ }^{\circ} \mathrm{C}$ cases shown in Figure 9 , slightly higher losses are overshadowed by significantly higher hydrogen conversion efficiency. Again referring back to Figure 5, at $100^{\circ} \mathrm{C}$ the hydrogen conversion efficiency is quite high.

The result is that total efficiency is highest at $100{ }^{\circ} \mathrm{C}$. Increasing the temperature beyond $100{ }^{\circ} \mathrm{C}$ results in a slight gain in hydrogen conversion efficiency but larger losses to the exhaust gas and environment. This is the reason for the lower total efficiency of the $150{ }^{\circ} \mathrm{C}$ and $165{ }^{\circ} \mathrm{C}$ cases in Figure 9. 
The effect of hydrogen concentration on total efficiency is shown in Figure 9a. Generally, total efficiency increases with hydrogen mole fraction in the feed gas. At low oil temperature (60 C), where the hydrogen conversion efficiency is significantly less than unity, the increase in total efficiency is due to an increase in heater temperature and the resulting improvement in the hydrogen conversion efficiency. At higher temperatures (>100 C), the increase in total efficiency with hydrogen concentration is due to reduced heat loss to exhaust gas. The effect of total gas flow rate when the hydrogen concentration is fixed at $10 \%$ is shown in Figure $9 \mathrm{~b}$. Not a large effect is shown for this parameter.
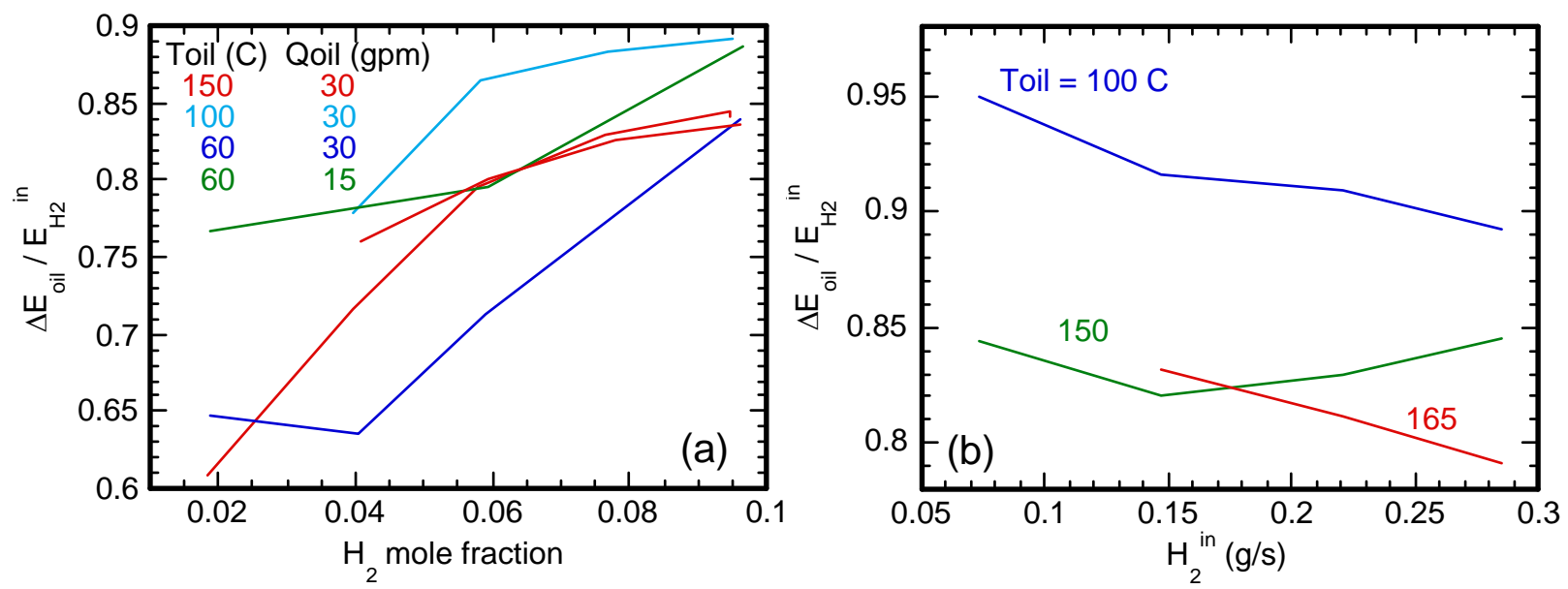

Figure 9. System efficiency as a function of the hydrogen mole fraction with a constant feed gas flow rate of $\mathbf{8 0} \mathrm{cfm}(\mathrm{a})$, and as a function of hydrogen flow rate for $\mathbf{1 0 \%}$ hydrogen in the feed gas and a $\mathbf{3 0} \mathrm{gpm}$ oil flow rate (b).

The catalytic heater was designed to produce a total efficiency of greater than $80 \%$. Considering the data in Figure 9 at the preferred operating condition of $10 \%$ hydrogen concentration, this goal was achieved for temperatures from $60^{\circ} \mathrm{C}$ up to $165^{\circ} \mathrm{C}$. At temperatures above $165^{\circ} \mathrm{C}$, the trend in the data indicates that losses would reduce the total efficiency below $80 \%$. Ways to reduce these losses will be discussed in the next section.

The system efficiencies shown in Figure 9a and b have some error bars associated with them, as indicated by the overall energy balance discussed below. That is, where the energy balance shows more energy is present than that available from hydrogen oxidation, the efficiency is probably less than that shown in Figure 9, while where the energy balance shows less energy than that available, the efficiency is probably larger.

\subsection{Overall Energy Balance}

Since energy must be conserved, the sum of the energy lost to the gas and environment along with the energy change in the oil, $\Sigma \mathrm{E}$, should equal the chemical energy released by the oxidation of hydrogen, $\Delta \mathrm{E}_{\mathrm{H} 2}$. The latter quantity is given by the product of the enthalpy of reaction with the difference in hydrogen flow rates between the feed gas and exhaust gas streams. Figure 10a 
shows the effect of oil temperature and flow rate on the ratio, $\Sigma \mathrm{E} / \Delta \mathrm{E}_{\mathrm{H} 2}$, as a function of the hydrogen mole fraction where the total gas flow rate was kept constant at $80 \mathrm{cfm}$. Figure 10b shows the effect of oil temperature on the energy ratio as a function of the hydrogen flow rate in the feed gas where the hydrogen mole fraction is kept constant at $10 \%$. The oil flow rate is 30 gpm in all cases. This ratio should be unity based on energy conservation, but as the results show, it ranges between $\sim 10 \%$ less than unity to $5 \%$ larger than unity. As discussed above, where this ratio exceeds unity, the heater efficiency is probably less than that shown in Figure 9, and where this ratio is less than unity the heater efficiency is probably greater than that shown in Figure 9. Although every effort was made to get the most accurate values, errors in any one of the energy terms that have been previously discussed would contribute to the lack of a total energy balance.
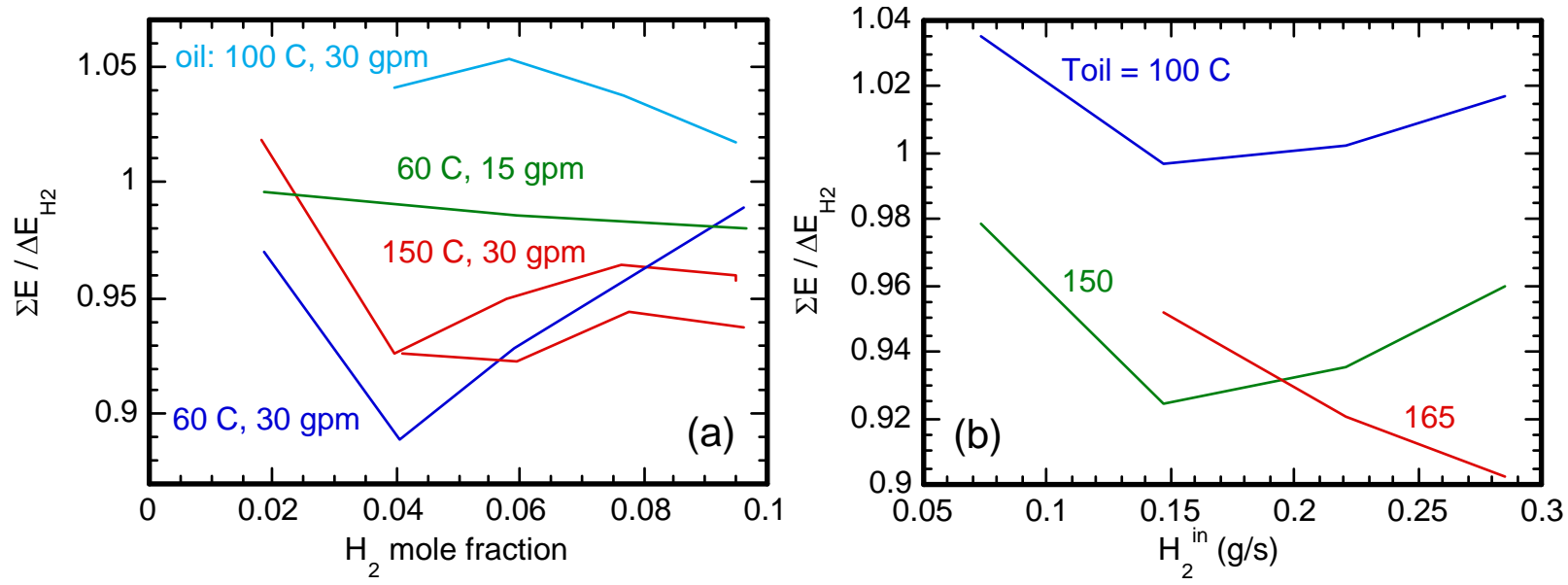

Figure 10: The overall energy balance as a function of the hydrogen mole fraction with a constant feed gas flow rate of $80 \mathrm{cfm}(\mathrm{a})$, and as a function of hydrogen flow rate for $\mathbf{1 0 \%}$ hydrogen concentration with a $30 \mathrm{gpm}$ flow rate (b).

Note that in Figure 10, most of the values show an energy balance below unity, suggesting that the corresponding total efficiency value in Figure 9 is low. Also, the lower total efficiency values seem to correlate with the lower energy ratios. For instance, the total efficiency values for the $165^{\circ} \mathrm{C}$ case in Figure 9b are lowest, but so are the energy ratio values in Figure 10b. The indication is that the total efficiency values may actually be higher. 


\section{EFFICIENCY IMPROVEMENT}

Having analyzed each of the contributions to the overall catalytic heater efficiency in the previous section provides a basis for this section on efficiency improvement. The goal for the catalytic heater design was a total efficiency of greater than $80 \%$. As shown in the previous discussion, this goal was achieved for the desired gas inlet condition of $10 \%$ hydrogen with nominal oil temperatures from $60{ }^{\circ} \mathrm{C}$ to $165^{\circ} \mathrm{C}$. However, each aspect of the catalytic heater was considered for improvement and several design changes were pursued in an effort to increase total efficiency. These will be discussed below.

\subsection{Incomplete Oxidation}

As shown in Figure 5, the fraction of hydrogen converted to heat in the catalytic reactor was quite high as designed. At temperatures above $100^{\circ} \mathrm{C}$, the hydrogen conversion efficiency was greater than $96 \%$. This does not provide a large opportunity for improvement, so further consideration was not given to this area.

\subsection{Heat Transfer to Gas}

\subsubsection{Recuperator Analysis}

Of the three pathways for energy loss from the catalytic heater, heat loss to exhaust gas was determined to be the largest. The gas heat recuperator had been designed to minimize this heat loss, but it appeared that the recuperator had not performed quite to the design specification. An analysis of the gas flow temperatures into and out of the recuperator can be used to understand the recuperator performance. The four temperatures are shown in Figure 11.

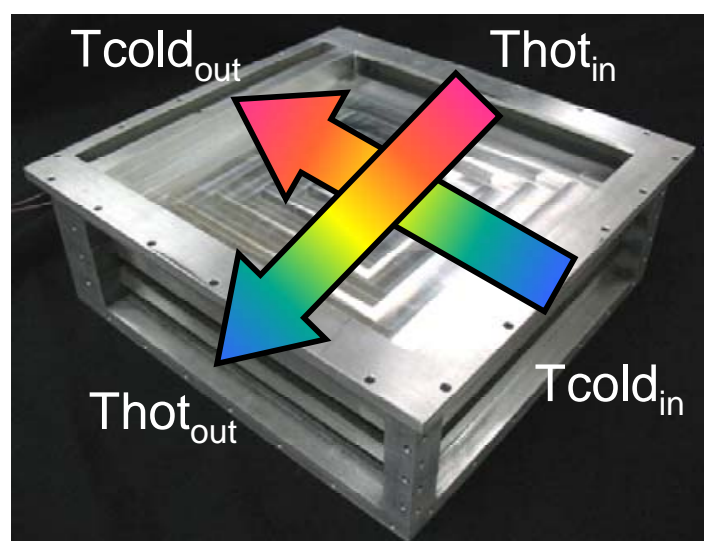

Figure 11: Recuperator temperatures used for performance calculations

The heat transferred to the cold inlet gas, Qcold, is calculated based on the gas mass flow, specific heat, and the measured temperatures Tcold $_{\text {in }}$ and Tcold ${ }_{\text {out }}$ as shown in Equation 6.

$$
\text { Qcold }_{=\dot{m} c_{p}}\left[\text { Tcold }_{\text {out }}-\text { Tcold }_{\text {in }}\right] \quad \text { Equation } 6
$$


This heat should be equal to the heat removed from the hot gas as it passes through the recuperator from the reactor. An analogous equation to Equation 6 can be used to calculate Qhot from Thot $_{\text {in }}$ and Thot ${ }_{\text {out }}$. The temperature difference between Thot ${ }_{\text {out }}$ and Tcold $_{\text {in }}$ is used to calculate the total heat loss to the gas, Qgas, as discussed in Section 2.4. Finally, the maximum heat transfer possible between the two gas streams, Qmax, is found from the temperature difference between Thot $_{\text {in }}$ and Tcold $_{\text {in }}$.

The efficiency of the recuperator is defined as the ratio of the actual heat transferred from the hot gas to the cold gas to the maximum possible heat transfer, Qmax. This efficiency was predicted to be about $75 \%$ based on the design calculations. Heat values and efficiencies based on measured gas temperatures are shown in Figure 12. The calculations used a mass flow rate based on the air flow meter and the corrected Brooks flow controller. Specific heat was calculated based on gas composition, but temperature dependence was ignored. Several conclusions can be drawn based on the plots in Figure 12. First, heat transfer to the cold gas stream does not match the heat loss from the hot gas stream for most conditions measured. Second, there is a significant effect of hydrogen concentration on the results. Finally, ignoring extraneous effects, the recuperator efficiency appears to be about 55\%.
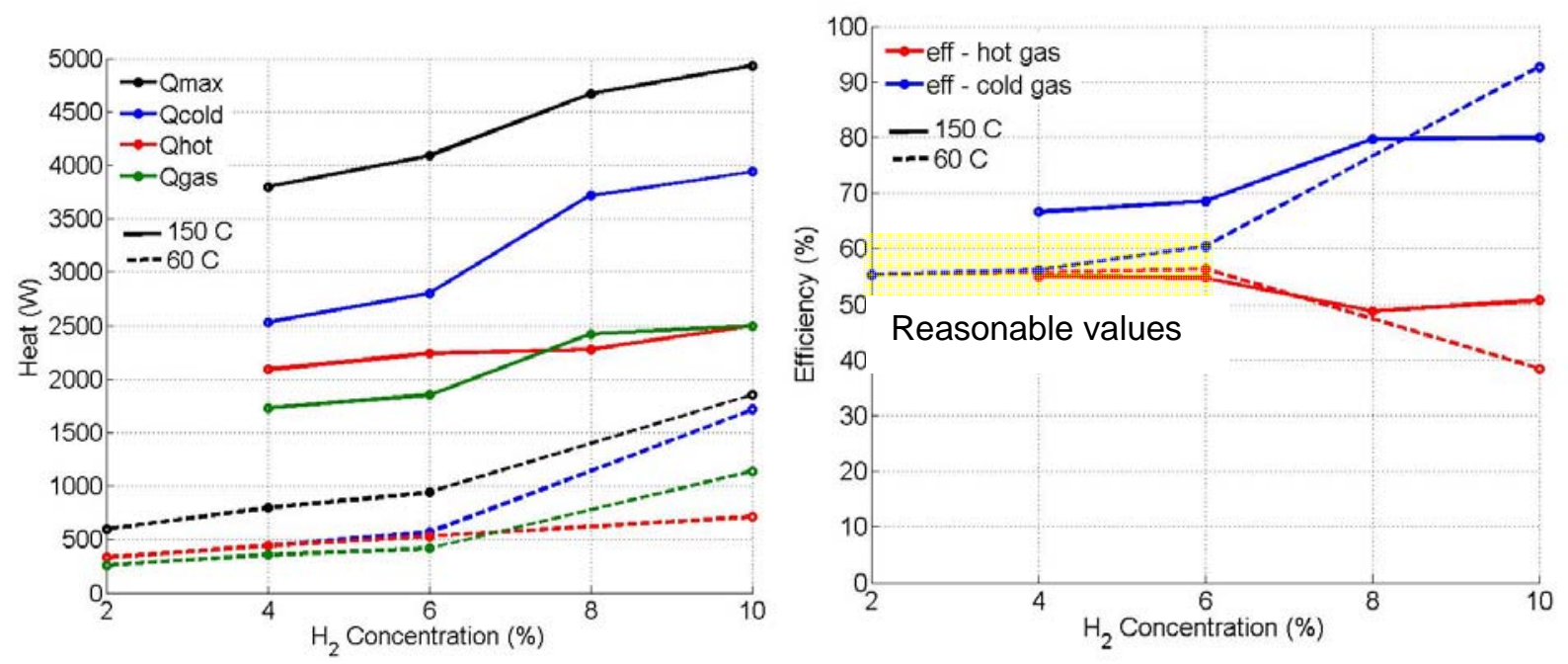

Figure 12. Heat flow in recuperator (left) and associated recuperator efficiency (right) for cases with oil temperature at $150^{\circ} \mathrm{C}$ and $60^{\circ} \mathrm{C}$

The plot on the left in Figure 12 shows that the calculations of Qcold (blue) and Qhot (red) only match at low temperature and low hydrogen concentration. The values are nearly equal, as would be expected, at $2 \%, 4 \%$, and $6 \%$ hydrogen concentration for the $60{ }^{\circ} \mathrm{C}$ case. The discrepancies between Qcold and Qhot may be caused by a combination of phenomena. One cause may be heat transfer from the reactor. At higher temperature, the reactor is significantly hotter than the average recuperator temperature. Rather than being an isolated heat exchanger, the recuperator is in direct contact with the reactor. Heat can conduct and radiate from the reactor to the recuperator and then be transferred to the cold gas stream. Another cause may be related to the exhaust gas path as it exits the reactor and enters the recuperator. Because the recuperator acts as a cover on one end of the reactor, the hot exhaust gases exit the reactor and 
impinge directly on the topmost recuperator layer. At that point the gas flow path must make a 90 degree turn to flow into the recuperator inlet plenum. Since the topmost recuperator layer is a cold feed gas layer, heat is transferred from the exhaust gas to this layer prior to the exhaust gas entering the recuperator inlet plenum where the Thot ${ }_{\text {in }}$ temperature is measured. So, this heat transfer is not accounted for in the recuperator energy balance calculations. Also, we would expect a fairly high heat transfer coefficient for this type of flow pattern. Finally, at hydrogen concentrations above 6\%, there appears to be a step up in the temperature of the hot exhaust gas. This could perhaps be due to a gas phase reaction that only occurs at higher hydrogen concentrations. Whatever the case, the higher exhaust gas temperature seems to magnify the previous effect and results in a cold gas heat gain that is higher than the hot gas heat loss.

Despite these discrepancies, a recuperator efficiency can be estimated based on the hot gas temperatures at the lower hydrogen concentration values. These values are highlighted in the right-hand plot in Figure 14, and indicate a recuperator efficiency of about $55 \%$. This value is significantly less than the expected $75 \%$ efficiency. The ultimate effect on the catalytic heater was that almost half of the heat lost to the exhaust gas was not recovered, resulting in a 7\% efficiency reduction. To better understand the recuperator performance and identify improvements, a detailed computation model of the recuperator was developed.

\subsubsection{Recuperator Modeling}

The recuperator model was developed to understand the details of the heat transfer occurring within it so that design improvement could be identified that would reduce the heat loss to the catalytic heater exhaust gas. Figure 13 shows the three-dimensional model of the recuperator. Due to the cross flow arrangement of the design, the model had to include a full set of (200) feed gas channels mated with a full set of (200) exhaust gas channels. In order to limit the size of the model, only one set each of the feed and exhaust gas channels was included, and only half of the height of each set of channels was considered where symmetry was assumed at the half-height cutting planes. Even with these limitations the model contained over 5 million elements and required 128 processors on a high performance computer to solve in a reasonable amount of time. Note that the model includes the solid (aluminum) domain where heat transfer is by conduction, as well as the gas domains where heat transfer is by conduction and convection. In addition to the symmetry conditions, boundary conditions specifying the inlet gas velocity and temperature were applied at the inlets of both the feed gas and exhaust gas channels. 

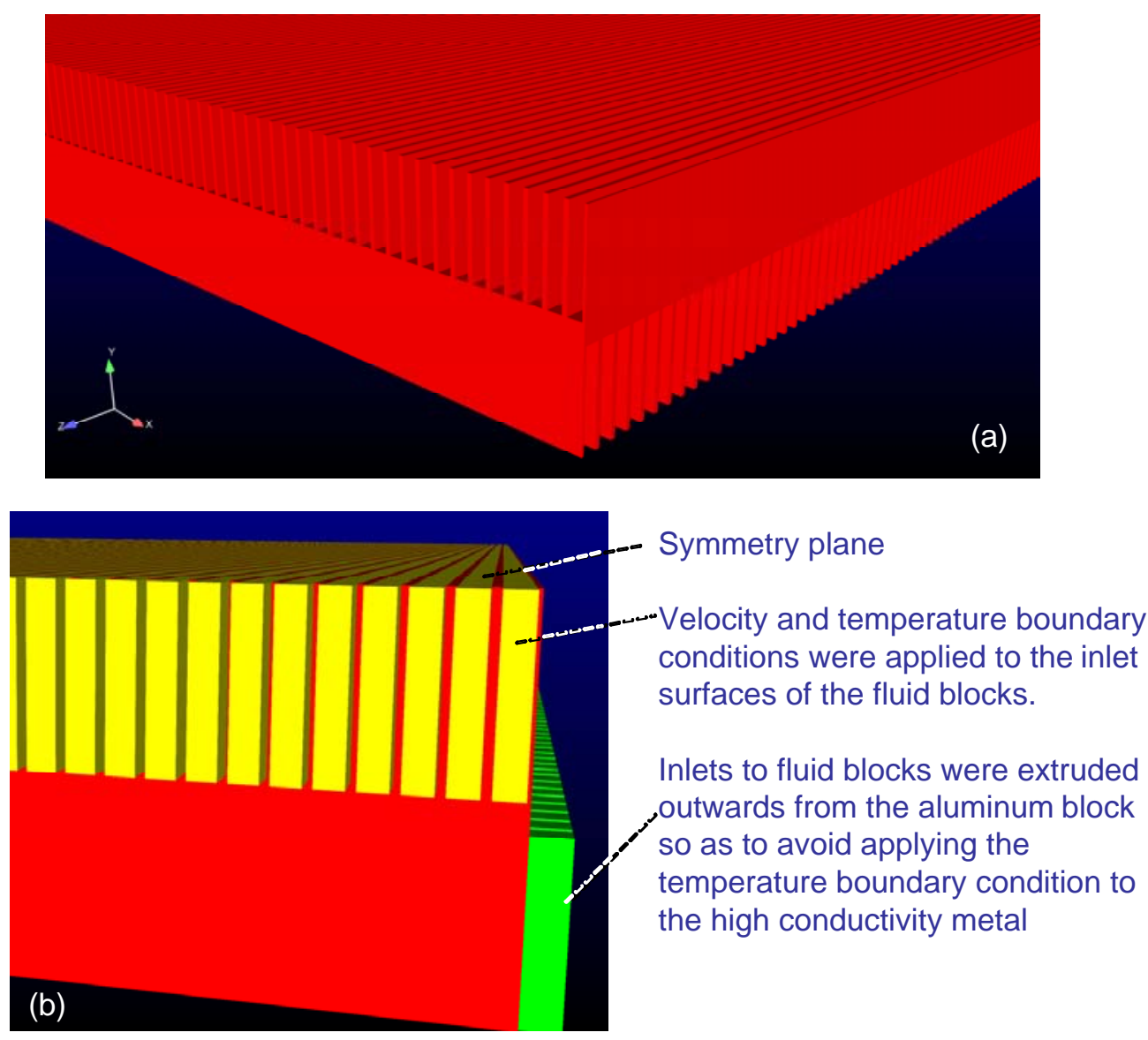

Figure 13: The thermal/fluid finite element model of the recuperator. The portion of the model representing the aluminum (a). The model where the gas domains are also shown (b).

As an example of the fidelity of the model, Figure 14 shows the velocity and thermal distributions in a cut-away of the model. Within each gas channel a parabolic velocity profile has developed where the velocity is zero at all gas-solid interfaces. The figure shows the feed gas channels (cold) on top and a cross section of one of the exhaust gas channels (hot) on the bottom. Although the velocity fields are similar for all of the channels, the thermal fields within the channels are very different. 


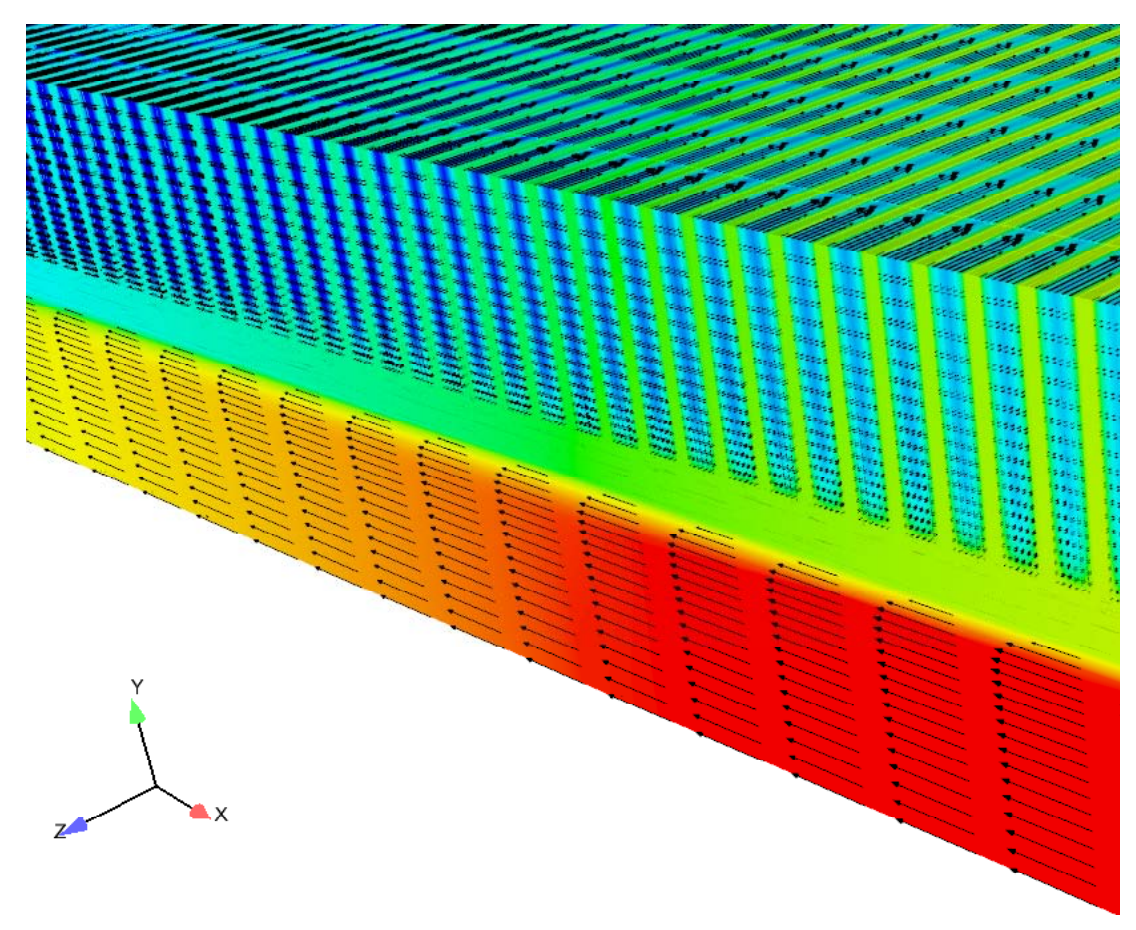

Figure 14: A cut-away of the model showing the thermal and fluid velocity fields in the
recuperator.

In order to assess the effects of various design parameters on the performance of the recuperator, a baseline case was defined. The case chosen was the full power $(30 \mathrm{~kW})$ mode of the catalytic heater at $150{ }^{\circ} \mathrm{C}$ where the gas flow rate was at a maximum with $10 \%$ hydrogen concentration. As discussed in the previous section, the recuperator gas temperature measurements for this case indicated a discrepancy between the feed gas heat gain and the exhaust gas heat loss. Possible reasons for this discrepancy have been discussed as well. So, for the model to predict the measured outlet temperatures, one of the inlet temperatures needed to be modified. For the following calculations we chose to increase the exhaust gas inlet temperature and use the measured feed gas inlet temperature. With these temperatures and the appropriate gas flow rates as boundary conditions, the model was run first in the as-built configuration.

Figure 15 shows the calculated temperature distribution in the recuperator. The temperature at the inlet to the feed gas channels is at a uniform value of $50^{\circ} \mathrm{C}$, while that at the inlet to the exhaust channels is at a uniform value of $210^{\circ} \mathrm{C}$. Due to the cross flow arrangement, the overall temperature distribution has a diagonal appearance, where the corner near the inlet to the feed channels and near the outlet of the exhaust channels is cold, while the corner near the outlet of the feed channels and the inlet to the exhaust channels is hot. Channel number labels are shown in Figure 15 and referred to in Figure 16, where feed channel \#1 is near the inlet to the exhaust channels and feed channel \#200 is near the outlet of the exhaust channels. Similarly, exhaust channel \#1 is near the inlet to the feed channels and exhaust channel \#200 is near the outlet of the feed channels. 


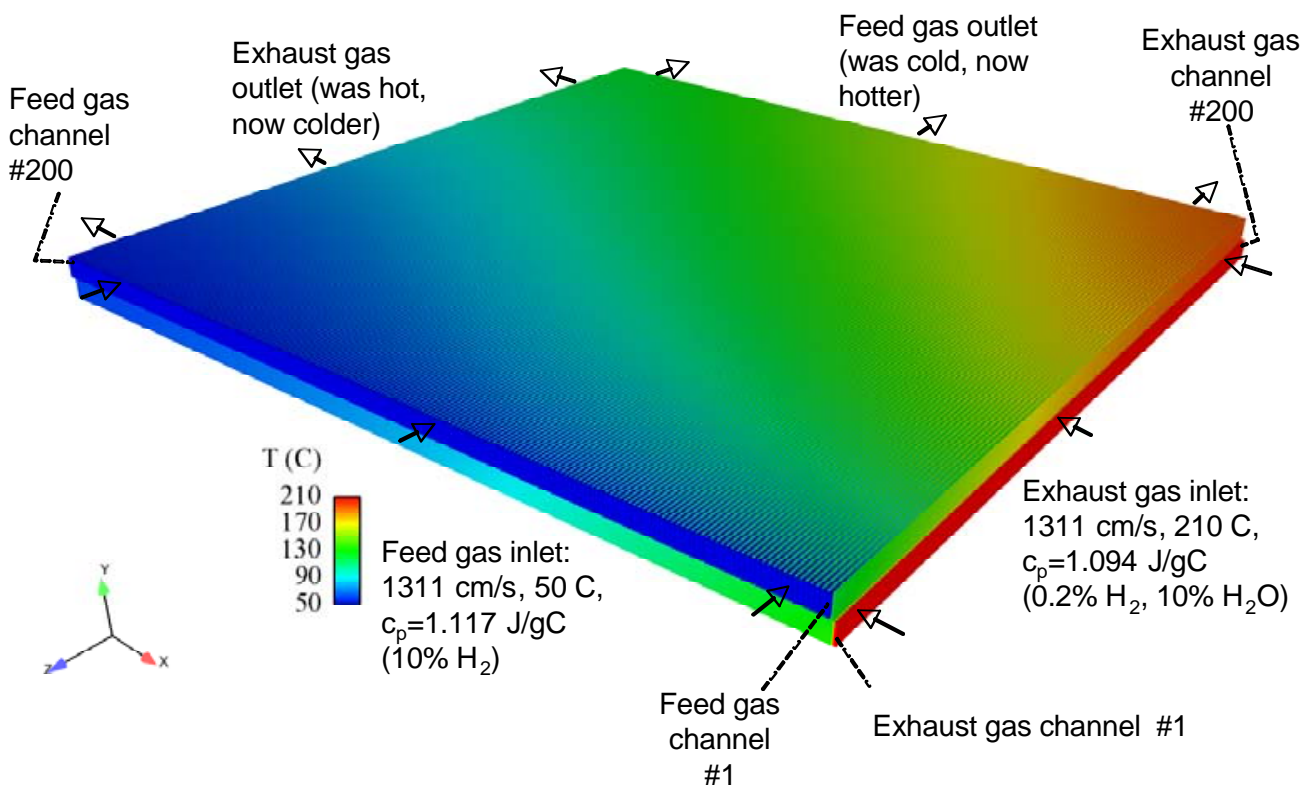

Figure 15: The predicted temperature distribution in the recuperator.

To check the model against experimental results the predicted outlet temperatures were compared to the measured outlet temperatures from the $150{ }^{\circ} \mathrm{C}, 10 \% \mathrm{H}_{2}$ case. The model outlet temperatures were obtained by taking a flow-rate-weighted average of the outlet temperatures from all of the gas channels. With the adjusted exhaust gas inlet temperature, the comparison between measured and calculated outlet temperatures is quite good as shown in Table 2. The recuperator efficiency that was calculated based on the model inlet and outlet temperatures was $65.3 \%$. Note that this is higher than the estimate made based on the experimental results due to effects not captured by the model. These effects include flow non-uniformity, heat loss to the environment, and heat transfer to/from the reactor.

Table 2: Comparison of Recuperator Model to Experimental Results

\begin{tabular}{|c|c|c|c|c|}
\hline & Feed Gas Tin & Feed Gas Tout & Exhaust Gas Tin & Exhaust Gas Tout \\
\hline Experiment & $50 \mathrm{C}$ & $147 \mathrm{C}$ & $176 \mathrm{C}$ & $111 \mathrm{C}$ \\
\hline Model & $50 \mathrm{C}$ & $154.5 \mathrm{C}$ & $210 \mathrm{C}$ & $103.2 \mathrm{C}$ \\
\hline
\end{tabular}

Although the model does not match perfectly with the experimental results, it can still be used to understand the heat transfer within the recuperator and compare the effects of varying design parameters. To gain a better understanding of the channel to channel heat transfer taking place in the recuperator, the results shown in Figure 15 were further post-processed. Figure 16 shows a set of temperature profiles along three of the feed gas channels, \#1, \#100 and \#200 (see Figure 15 for the channel numbering scheme). Also shown are the exhaust gas temperatures at points beneath these feed gas channels (see the left side of Figure 16 for clarification). The feed gas temperatures are shown as solid curves, while the exhaust gas temperatures are shown as dashed curves. Ideally, the feed gas temperature at the outlet of the channels $(z=20)$ would be equal to the corresponding exhaust gas temperature. That is, the temperature difference between like colored solid and dashed curves at $\mathrm{z}=20$ is indicative of incomplete heat transfer and suggests that the design could be improved. 


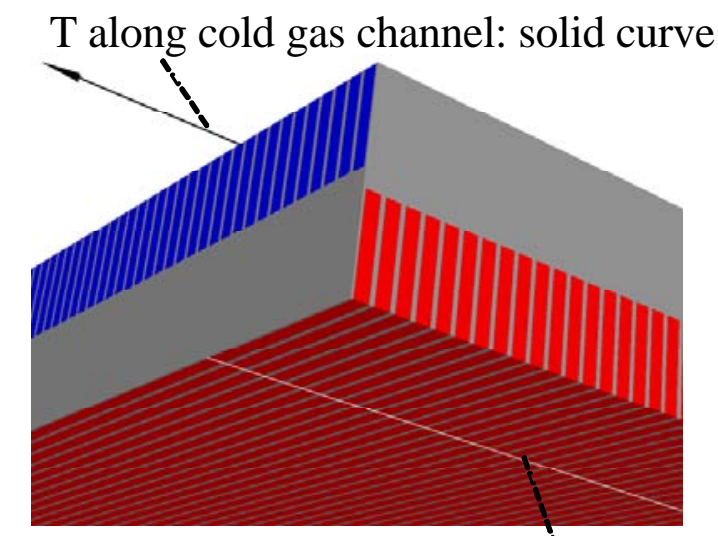

T across hot gas channels: dashed curve

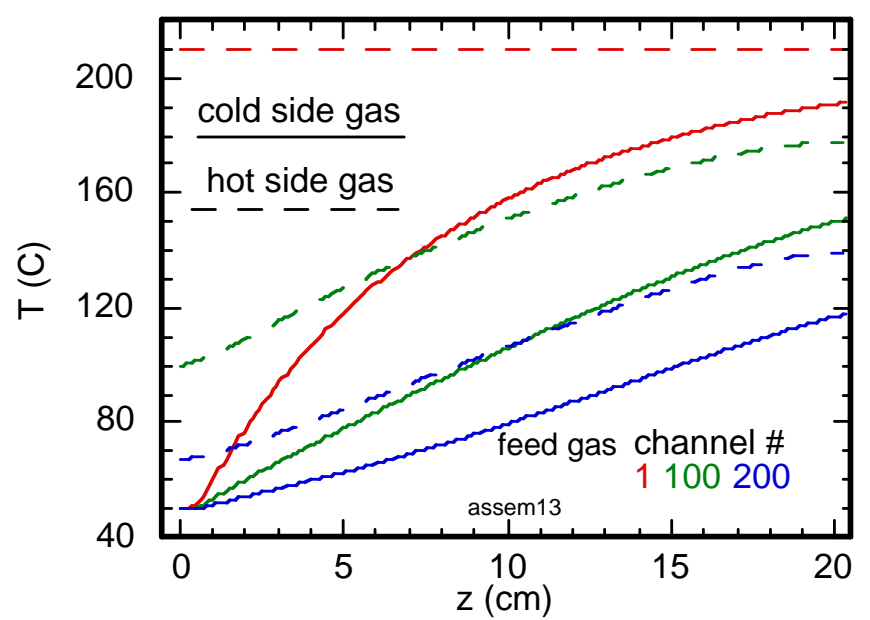

Figure 16: The predicted temperature profiles in the recuperator.

To see where improvements in the design could be made, calculations were carried out to explore the effect of changes to some of the design parameters. The parameters that were considered included fin thickness, number of fins per inch (fpi), number of channel layers, and fin thermal properties. These were all parameters that could be modified without significantly affecting the recuperator or catalytic heater design. Other parameters, such as channel length, were constrained by the design of the heater.

Fin thickness can affect a performance parameter known as fin efficiency. This parameter is a measure of the how well the fins transfer heat from the base plate. An indication of fin efficiency is the temperature difference between the base plate and the end of the fin. This value should be small, especially compared to the temperature difference between the base plate and the gas. The recuperator model was used to examine these values. Figure 17 shows a set of temperature profiles parallel to feed gas channel \#100, one down the middle of the gas domain (mid-gas), one down the middle of the fin (mid-fin), and another underneath the feed channel through the middle of the plate that separates the feed channels from the exhaust channels (midplate). The left side of Figure 17 shows a schematic to help clarify the positions of these three profiles. The feed channels are oriented perpendicular to the page in this schematic while the exhaust channels are oriented in the plane of the page and beneath the feed channels. The temperature profiles show that the difference between the fin and the plate temperatures is small compared to that between the gas and the plate. This indicates that the fin conductance is good and very little improvement to the design can be obtained by increasing the thickness of the fins (0.01 inch). In fact, this result indicates that the fins could probably be thinner. 

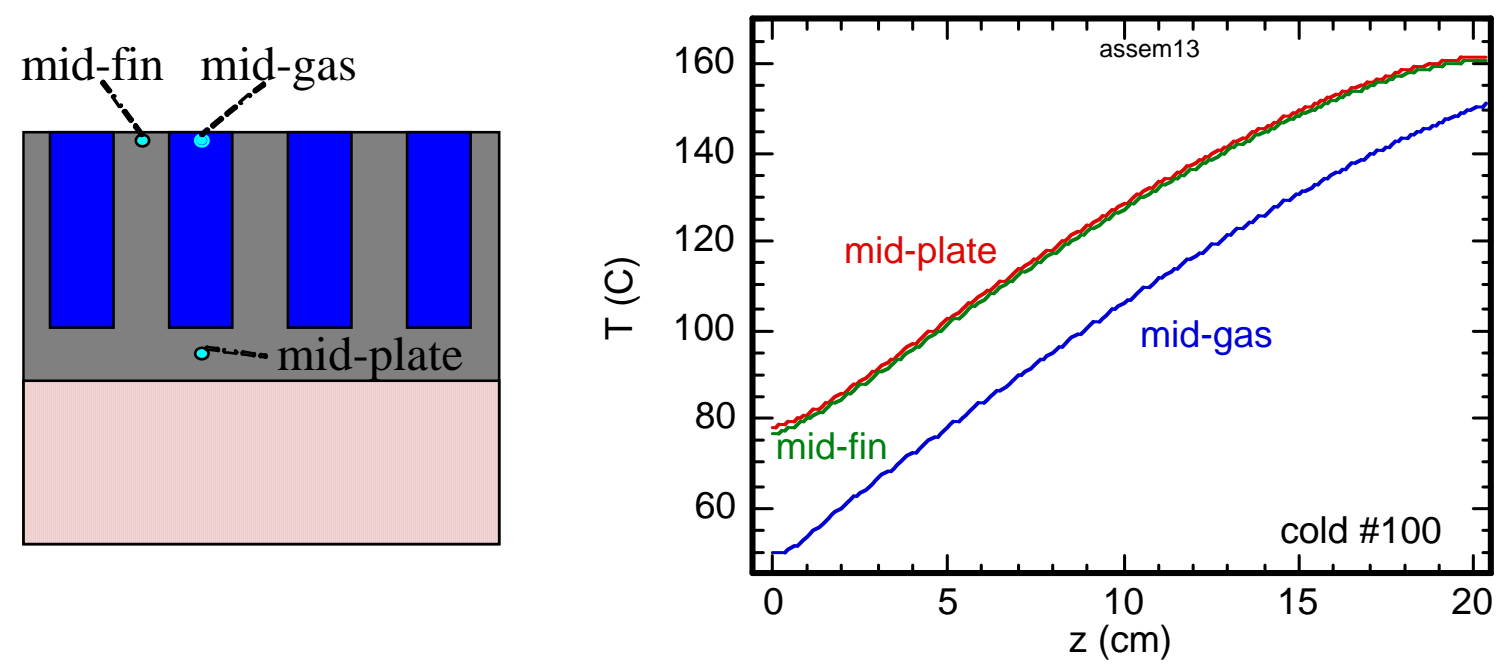

Figure 17: Predicted temperature profiles in the recuperator showing the fin effectiveness.

Since the fin conductance was shown above to be more than adequate, a thinner fin, allowing for a larger number of fins that were closer together, was considered. The as-built design used 25 fins per inch (fpi) and a fin thickness of 0.01 inch, so a design with 50 fpi and a fin thickness of 0.005 inch was considered. This would increase the recuperator surface area and provide better heat transfer between the feed and exhaust gases. Also, the original design had three layers of feed gas channels and three layers of exhaust channels, so a design that had four layers of each was considered. Assuming the same total gas flow rate, the gas velocity is reduced by splitting the gas into four rather than three layers of channels, resulting in a longer residence time and allowing the heat transfer to become more complete. Finally, the effect of material (i.e. thermal conductivity) that the recuperator is made from was explored. The purpose of the recuperator is to heat the feed gas from a cold inlet temperature to a hot outlet temperature, while the exhaust gas is cooled from a hot inlet temperature to a cold outlet value. That is, the recuperator should promote the development of a large temperature difference between inlet and outlet of the feed gas, and likewise for the exhaust gas. The as-built design used aluminum (Al), which is a good conductor that acts to limit the development of this large temperature difference. So, stainless steel was considered as well as an anisotropic material having large conductivity promoting good heat transfer from the exhaust gas channels to the feed gas channels, but poor conductivity in the directions parallel to both the feed and exhaust gas flow directions.

Table 3 shows the results of this parameter study in the form of two metrics, an efficiency defined in terms of gas inlet and outlet temperatures as $\left(T_{\text {feed out }}-T_{\text {feed in }}\right) /\left(T_{\text {exhaust in }}-T_{\text {feed in }}\right)$, and the pressure drop required to push the gas through the recuperator. The efficiency provides a measure of the heat transfer between the feed and exhaust gases. A value of zero indicates that there is no heat transfer between feed and exhaust gases, and a value of unity means that the maximum possible amount of heat transfer between the exhaust and feed gases was obtained, i.e. the feed gas is heated to the inlet temperature of the exhaust gas. This is only theoretically possible for a counter flow heat exchanger, and not for the cross-flow arrangement of the recuperator. The pressure drop is important because a blower is required to push or draw gas through the recuperator, and the size and power requirements for the blower increase with the pressure drop. 
The results for the as-built design are shown in the box in the upper left of Table 3 , for which the efficiency is 0.653 and the pressure drop is 0.15 psi. By going from three to four layers of channels there is only a modest improvement in efficiency, along with a reduced pressure drop. This small improvement comes at the cost of a larger recuperator that requires more space which may not be warranted. The next column of values shows the effects of an anisotropic thermal conductivity. A modest improvement in efficiency is shown for the 3 layer case, indicating that the effect of heat conduction through the hardware on the temperature difference that develops between inlet and outlet gas is small. Using a 4-layer design with the anisotropic material further improves the recuperator performance, but the improvement may still not be enough to warrant the increase in size. Also, it is not clear that a real material could produce the anisotropy that was modeled. This case was run to show the limit of the thermal conductivity effect. The third column shows the results for an all stainless steel, 4-layer design which actually performs worse than an aluminum design due to the reduced heat conduction from the hot exhaust gas to the cold feed gas.

The result with the most promise is shown in the fourth column. A design with 50 fpi would provide a significant increase in efficiency, although at the cost of a significantly larger pressure drop. This is a common problem with all heat exchangers, where for a given total size the heat transfer cannot be increased without also increasing the pressure drop. A trade study would need to be conducted that takes into account the effect of the pressure drop on the size of the blower before this path should be pursued. However, there may be a fpi and fin thickness combination that produces an optimum solution.

Table 3: Predicted efficiencies and pressure drops (psi) in the recuperator for various design parameters ( ${ }^{*}$ as-built parameters).

\begin{tabular}{|c|c|c|c|c|c|}
\hline \multicolumn{2}{|c|}{ Fin / fpi } & \multicolumn{3}{|c|}{$0.01^{\prime} / 25^{*}$} & $0.005^{*} / 50$ \\
\hline \multicolumn{2}{|c|}{$\mathrm{k}(\mathrm{W} / \mathrm{cmK})$} & $\begin{array}{c}1.8^{*} \\
(\mathrm{Al})\end{array}$ & $\begin{array}{c}0.1 / 1.8 \\
\text { (Anisotropic) }\end{array}$ & $\begin{array}{c}0.15 \\
\text { (stainless steel) }\end{array}$ & $\begin{array}{c}1.8 \\
(\mathrm{Al})\end{array}$ \\
\hline \multirow{2}{*}{ Efficiency / $\Delta \mathrm{p}$} & 3 layers & $0.653 / 0.15$ & $0.681 / 0.15$ & $\mathrm{NA}$ & $0.761 / 0.58$ \\
\cline { 2 - 6 } & 4 layers & $0.677 / 0.11$ & $0.719 / 0.11$ & $0.658 / 0.11$ & $\mathrm{NA}$ \\
\hline
\end{tabular}

Based on the above results and discussion, it appears that the as-built design cannot be improved significantly without affecting another important performance attribute such as volume or pressure drop. However, this analysis has been constrained to a cross flow configuration. A counter flow configuration would perform better, but it would come at a cost of increased complexity in the design of the manifolds required to distribute the feed and exhaust gases to the alternating layers of gas channels. Pursuit of such a design would also require a trade study between efficiency improvement and design complexity.

\subsection{Heat Transfer to Environment}


As discussed in section 2.5, the heat lost to the environment from the catalytic heater was fairly low. At $150{ }^{\circ} \mathrm{C}$, the heat loss experiment showed a value of about $500 \mathrm{~W}$. This is less than $2 \%$ of the inlet hydrogen energy. The low heat loss value can be attributed in part to the compact geometry of the heater. However, the primary reason for this low value was the insulation. The catalytic heater was insulated with vacuum insulation panels (VIPs).

VIPs consist of a micro or nano-porous material enclosed in a film barrier that is evacuated to $~ 1$ mbar. Fumed silica and aerogels are the most widely used core materials. At vacuum, thermal conductivities are reduced by a factor of 5 or more so that room temperature conductivities of $<$ $0.005 \mathrm{~W} / \mathrm{mK}$ are achieved. This is equivalent to an $\mathrm{R}$ value of 29 per inch of insulation.

The insulation panels for the catalytic heater were supplied by Nanopore Inc., Albuquerque, NM. Nanopore is the only producer of nanoporous carbon-silica vacuum insulation panels in the U.S. with over 10 years of experience. Small production of custom designs is their specialty and they had experience with high temperature applications. Additionally, they could produce panels in limited custom shapes.

Due to the high R value of the panels, they only needed to be 0.75 " thick and did not greatly increase the volume of the catalytic heater. Since the use of these advanced insulation panels resulted in a very low heat loss, little room for improvement remained. Thus, further work in this area was not conducted.

\subsection{Heat Transfer to Oil}

Thus far, we have considered improvements to the catalytic heater design that would reduce the energy loss terms. Another approach is to consider design improvements that would increase the heat transferred to the oil stream. To do so requires an understanding of this heat transfer path. The primary source for heating the oil is the exothermic hydrogen oxidation reaction occurring on the gas side fin surfaces. Heat produced on these surfaces must travel by conduction through the aluminum fins and plates to the oil side fin surfaces. At that point, the heat is transferred to the oil through a combination of convective and conductive heat transfer. A secondary source for heating the oil is from the hot gas stream. This heat transfer occurs at the far end of the fin channels where the catalytic reaction is slow due to the depleted reactants. In this region of the reactor, heat will be transferred from the gas to the oil side through a combination of convection and conduction as long as the gas stream is hotter than the oil stream.

If we consider the primary heat transfer path, the oil heat transfer can be improved if either the fin conduction or the oil side convection/conduction are improved. The net result of achieving either of these improvements would be a reduced gas side fin temperature for a given oil side temperature and heat transfer rate. This would, in turn, reduce the heat gained by the exhaust gas and ultimately reduce the heat lost to the exhaust gas.

While it is certainly possible that both fin conduction and oil convection/conduction could be improved, we should note that the reactor design was the result of significant computational 
simulation which was validated through prototype evaluation. The design consists of nine fin channel layers in a co-flow configuration. The gas side fin layers contain 0.032 ” thick fins at a density of 6 fpi. The oil side fin layers contain 0.010 " thick fins at a density of 25 fpi. These layers were designed to balance gas side heat production with oil side heat transfer. While the design was not rigorously optimized, the computational results indicated good performance.

To improve fin heat conduction would, to first order, simply require thicker fins on the gas or oil sides or perhaps both. If significant changes were not made, this change would not drastically change the design. For the oil side heat transfer, any improvement would likely come at the cost of an increased pressure drop. This could perhaps be tolerated, but would require a trade study.

Another path to improve oil heating is through flow uniformity. As previously mentioned, a significant design effort was conducted to uniformly distribute single oil and gas streams into the hundreds of individual fin channels that make up the reactor. Again, computational simulation was used heavily for this design effort which resulted in the use of large distribution manifolds and flow diffusers at key locations. To understand the implication of non-uniform flow, consider the case where both gas and oil streams are distributed non-uniformly and are mismatched. That is, a region of high gas flow, thus high heat generation, occurs where the oil flow is at a minimum. The result is low heat transfer to the oil and high local temperatures that may exceed design constraints.

While test results from the catalytic heater suggest that flow uniformity in the reactor is good, improvements could be made. However, like an improvement in heat transfer, an increase in flow uniformity is likely to come at the cost of increased pressure drop. So, like the heat transfer case, this would need to be performed in a system level trade study. 


\section{SUMMARY AND CONCLUSIONS}

Funded by General Motors, Sandia National Labs has developed a high efficiency, compact heater that uses the catalytic oxidation of hydrogen to provide heat to a metal hydride hydrogen storage system. The heater was designed to transfer up to $30 \mathrm{~kW}$ of heat from the catalytic reaction to a circulating heat transfer fluid. The fluid then transfers the heat to one or more of the hydrogen storage system modules to drive off the chemically bound hydrogen. A performance characterization and improvement study of the catalytic heater was carried out and described.

All of the energy streams, whether chemical or thermal, entering or exiting the catalytic heater were investigated to produce an overall energy balance and improve an initial estimate of the heater efficiency. These streams included the chemical energy in the feed gas and exhaust gas streams, the thermal energy in the feed gas and exhaust gas streams, the thermal energy in the inlet and outlet oil streams, and finally the combined convective and radiative thermal energy stream to the environment. Calculated values of these energy streams or differences between them based on measured temperatures, fluid flow rates, and fluid properties were examined for accuracy. Measurement errors were taken into account and in some cases redundant measurements were made.

For the chemical energy in the feed gas, a 7\%-9\% systematic error of the hydrogen flow controller was corrected using a more accurate instrument. This correction significantly improved the overall energy balance. The chemical energy in the exhaust was found to be quite low for most conditions of interest. Less than $7 \%$ of the inlet hydrogen remained in the exhaust gas for heater temperatures above $100{ }^{\circ} \mathrm{C}$ and less than $2 \%$ remained above $150{ }^{\circ} \mathrm{C}$. This indicated that the catalyst coating and reactor design performed as desired.

Thermal energy gains in the gas stream from feed to exhaust were considered losses and were expressed as a percentage of the feed gas chemical energy. These energy losses varied from $2 \%$ at $60{ }^{\circ} \mathrm{C}$ oil temperature to $8 \%$ at $165^{\circ} \mathrm{C}$. Although these values are lower than original estimates due to more rigorous data analysis, they are higher than expected and the trend suggests that losses to gas heating would be even larger at higher temperature. The gas heat recuperator was designed to minimize heat lost to the exhaust gas. Design calculations suggested that $75 \%$ of the thermal energy in the exhaust gas could be recovered, but measurements showed this value to be about 55\%. The discrepancy between these values was investigated with a detailed, three-dimensional computational model of the recuperator. The results suggested that the more simplistic design calculations over-predicted the performance, but that the measurements may have underestimated the performance since heat is transferred from the hot exhaust gas to the cool feed gas upstream of the exhaust gas temperature measurement. The detailed model predicted a recuperator efficiency of $65.7 \%$.

Energy lost by the catalytic heater to the environment was characterized through a transient heat loss experiment. The temperature-dependant value was found to vary from about $200 \mathrm{~W}$ at 100 ${ }^{\circ} \mathrm{C}$ to about $800 \mathrm{~W}$ at $170{ }^{\circ} \mathrm{C}$. This value was much lower than previous estimates which were based on the difference between other measured values. The experimentally determined values seemed more reasonable given the compact size of the heater and the use of vacuum insulation panels. 
The primary function of the catalytic heater was to transfer heat from gas side catalytic hydrogen oxidation to the flowing oil stream. Thus, heat transfer to the oil was carefully characterized. Thermocouples were calibrated and redundancy was used. A redundant oil flow measurement was also made. In addition, oil properties were measured to check the manufacturer's published values. The combined result was that previous estimates were shown to be low by about $2 \%$. Based on the corrected results for oil heat gain and feed gas chemical energy, the total efficiency of the catalytic heater was determined to exceed the design goal of $80 \%$ for oil temperatures from $60{ }^{\circ} \mathrm{C}$ to $165{ }^{\circ} \mathrm{C}$ with a feed gas composition of $10 \%$ hydrogen. While an overall energy balance could not be shown for all operating conditions, the energy balance error indicated higher heater efficiency than had been calculated for many of those conditions.

Beyond performance characterization, a number of design improvements were considered for the catalytic heater. Due to the high hydrogen conversion efficiencies demonstrated, improving this aspect of the design seemed unlikely. Likewise, the relatively low measured heat loss to the environment suggested that insulation improvements were unnecessary. The highest payoff improvement would be to decrease the gas heat loss by modifying the recuperator design or increasing the heat transfer efficiency of the reactor. While several recuperator design modifications showed promise based on computation simulations, each would come at a price. Using a higher fin density would result in a higher pressure drop, adding an extra fin layer would result in a larger recuperator, and changing to a counter-flow configuration would add complexity. Similarly, to improve the reactor heat transfer efficiency would likely result in a higher oil side pressure drop. Design trade studies would need to be conducted at the system level to determine whether any of these modifications should be further explored. 


\section{REFERENCES}

1. T. A. Johnson and M. P. Kanouff, Parameter Study of a Vehicle-scale Hydrogen Storage System, SAND2010-2140, Sandia National Laboratories, Livermore, CA, April, 2010

2. T. A. Johnson and D. E. Dedrick, Durability Study of a Vehicle-scale Hydrogen Storage System, SAND2010-XXXX, Sandia National Laboratories, Livermore, CA, (in preparation for publication)

3. T. A. Johnson, S. W. Jorgensen, and D. E. Dedrick, A Vehicle-Scale Sodium Alanate Hydrogen Storage Demonstration System, (in preparation for publication) 


\section{DISTRIBUTION}

4 Scott Jorgenson

Chemical and Environmental Sciences

General Motors R\&D, Planning and Fuel Cell Activities

Mail Code: 480-106-269

30500 Mound Road

Warren, MI. 48090-9055

4 Monterey Gardiner (DOE/EERE)

Forrestal Building

U.S. Department of Energy

1000 Independence Ave., S.W.

Washington, DC 20585

$\begin{array}{llll}1 & \text { MS0824 } & \text { Joel Lash } & 1510 / 1512 \text { (electronic) } \\ 1 & \text { MS0836 } & \text { Terry Aselage } & 1514 \text { (electronic) } \\ 1 & \text { MS9001 } & \text { Chris Moen } & 8005 \text { (electronic) } \\ 1 & \text { MS9153 } & \text { Mike Hardwick } & 8220 \text { (electronic) } \\ 1 & \text { MS9035 } & \text { Paul Spence } & 8224 \text { (electronic) } \\ 1 & \text { MS9054 } & \text { Bob Carling } & 8300 \text { (electronic) } \\ 1 & \text { MS9054 } & \text { Art Pontau } & 8360 \text { (electronic) } \\ 1 & \text { MS9052 } & \text { Jay Keller } & 8367 \text { (electronic) } \\ 1 & \text { MS9409 } & \text { Daniel Dedrick } & 8365 \text { (electronic) } \\ 1 & \text { MS9409 } & \text { Neal Fornaciari } & 8365 \text { (electronic) } \\ & & & \\ 2 & & & 8944 \\ 2 & \text { MS9018 } & \text { Central Technical Files } & \end{array}$





\section{Sandia National Laboratories}

